\title{
RBP-J Deficiency Promoted The Proliferation and Differentiation of CD133-Positive Ependymal Cells In Vitro and In Vivo Studies
}

\author{
Xin Ye \\ Wenzhou Medical University \\ Mengyi Li \\ Wenzhou Medical University \\ Wei Bian \\ Wenzhou Medical University \\ Junwei Li \\ Wenzhou Medical University \\ Ting Zhang \\ Wenzhou Medical University \\ Peng Zhou \\ Wenzhou Medical University \\ Huairui Cui \\ Wenzhou Medical University \\ Yu-Qiang Ding \\ Wenzhou Medical University
}

Shuangshuang Qi

Wenzhou Medical University Second Affiliated Hospital

Anting Wu

Wenzhou Medical University

Min Liao

Wenzhou Medical University

Chenyou Sun ( $\nabla$ sunchenyou1972@aliyun.com )

Wenzhou Medical University https://orcid.org/0000-0002-4563-1987

\section{Research Article}

Keywords: CD133-positive ependymal cell, Notch signaling pathway, RBP-J, Neural stem cell, Cell proliferation and differentiation

Posted Date: August 24th, 2021 
DOl: https://doi.org/10.21203/rs.3.rs-663313/v1

License: (c) (1) This work is licensed under a Creative Commons Attribution 4.0 International License. Read Full License 


\section{Abstract}

Although the ependymal cells were reported to have the characteristics of neural stem cells (NSCs), the properties of CD133-ependymal cells have not been uncovered, in particular, it is largely unknown about the effect of Notch signaling pathway on the neurogenesis of CD133-positive ependymal cells. By using the transgenic mouse and primarily cultured ependymal cells, we found that the immunoreactivity for prominin-1/CD133 was exclusively localized in the subventricular zone (SVZ) and ependymal layer of ventricles, moreover, most CD133-positive ependymal cells were co-labeled with Nestin. In addition, RBP-J, a key nuclear effector of Notch signaling pathway, was highly active in CD133-positive ependymal cells. Our results demonstrated that CD133-positive ependymal cells can differentiate into the immature and mature neurons, in particular, the number of CD133-positive ependymal cells differentiating into the immature and mature neurons was significantly increased following the deficiency or interference of RBP$\mathrm{J}$ in vivo or in vitro. By using real-time QPCR and Western blot, we found that RBP- $\mathrm{J}$ and Hes1 were downregulated while Notch1 was up-regulated in the expression levels of mRNAs and proteins following the deficiency or interference of RBP-J in vivo or in vitro. These results demonstrated RBP-J deficiency promoted the proliferation and differentiation of CD133-positive ependymal cells. Therefore, we speculated that RBP-J could maintain CD133-positive ependymal cells in the characteristics of NSCs possibly by regulating Notch1/RBP-J/Hes1 pathway.

\section{Introduction}

The new-born neurons exist in the two discrete locations throughout life, namely the sub-granular zone (SGZ) of hippocampal dentate gyrus and the subventricular zone (SVZ) of lateral ventricle (LV) (Xie et al. 2017). In the LV-SVZ, the neural stem cells (NSCs) require a finely-tuned balance between the self-renewal and differentiation throughout life (Chojnacki et al. 2009; Pfenninger et al. 2011).

As an important surface marker of stem cells, CD133 protein was originally described as "Prominin-1" in the murine embryonic NSCs (Weigmann et al. 1997; Fargeas et al. 2003), the putative NSCs of cerebellum (Lee et al. 2005) and the embryonic neuroepithelial cells (Uchida et al. 2000; Marzesco et al. 2005). In addition, CD133 was shown in the human fetal or adult myogenic and hematopoietic stem and progenitor cells (Miraglia et al. 1997). Previous studies have revealed that CD133 immunoreactivity was mainly distributed in the ventricular surface during the embryonic cortical development and in the early postnatal stage, as well as in the ependymal cells of adult brain (Pfenninger et al. 2007; Coskun et al. 2008; Pfenninger et al. 2011; Luo et al. 2015). Another study, however, reported that not all CD133-positive ependymal cells can maintain the activity of NSCs (Codega et al. 2014).

In addition to the LV-SVZ, our study found that much more neural progenitor cells (NPCs) were distributed around the third ventricle (3V)- and cerebral aqueduct (Aq)-SVZ following an intranigral injection of 6hydroxydopamine (6-OHDA) (Xie et al. 2017). Nevertheless, 6-OHDA-induced an increase in the NPCs of LV-, 3V and Aq-SVZ could not keep up with the decreasing levels of dopaminergic neurons and their axon terminals in the substantia nigra and striatum (Xie et al. 2017; Wang et al 2019; Chen et al. 2020). 
Carlen et al. (2009) reported that the murine LV-ependymal cells generated the neuroblasts and astrocytes once the stroke, injury or inhibition of Notch pathway has developed, although they were lack of selfrenewal potential under physiological conditions. Since an incomplete neurogenesis of NSCs or NPCs could not supply much more new-born neurons, the manipulation of neurogenesis will become very critical to restore the lesioned neurons in the fetal or adult brains (Weill-Engerer et al. 2002; Hattiangady and Shetty 2008; Ehm et al. 2010).

In a normal condition, the maintenance, proliferation and differentiation of the NSCs are tightly controlled under Notch signaling pathway, which is essential for the neurogenesis of developing mammalian brain (Furukawa et al. 2000; Scheer et al. 2001; Blanpain et al. 2006; Louvi and Artavanis-Tsakonas 2006; Mizutani et al. 2007; Song et al. 2007). Among the established components of Notch signaling pathway, RBP-J serves as a key and essential integrator, as a DNA-binding transcription factor of signal-binding protein recombination (Han et al. 2002; Bray 2006). Once Notch ligands bind to their receptors, the intracellular domain of Notch (NICD) is released, and then translocated into the nucleus, where NICD-RBP$\mathrm{J}$ complex is formed (Shi et al. 2012). NICD-RBP-J complex could activate such target genes as Hes 1 and Hes5, which represses the neuronal differentiation and maintain NSCs or NPCs in a pluripotent state (Kageyama and Ohtsuka 1999; Bertrand et al. 2002; Yoon and Gaiano 2005; Louvi and ArtavanisTsakonas 2006; Imayoshi et al. 2008).

Ehm et al. (2010) reported that the differentiation of adult mouse hippocampal NSCs, which held a highly active Notch/RBP-J signaling pathway, was significantly increased at 3 weeks following a conditional RBP-J inactivation. Carlen et al. (2009) reported that Notch signaling pathway could maintain the ependymal cells in a quiescent state under normal conditions. Once Notch signaling pathway was inhibited, the ependymal cells exited the cell cycle and then differentiated into the premature and mature neurons. Nevertheless, it has not been fully elucidated how Notch signaling pathway modulates the neurogenesis of CD133-positive ependymal cells in the adult SVZ and ependymal layer of ventricles (Hitoshi et al. 2002; Yamamoto et al. 2003; Duncan et al. 2005; Basak and Taylor 2007; Mizutani et al. 2007; Andreu-Agullo et al. 2009).

By immunohisto (cyto)-chemical staining, real-time qPCR and Western blot, we sought to determine the effect of RBP-J deletion or interference on the proliferation and differentiation of CD133-positive ependymal cells, as well as observed the expression profiles of essential components in Notch/RBP-J signaling cascade including Notch receptor (Notch1), RBP-J and its target Hes1 in vitro and in vivo.

\section{Materials And Methods}

\section{Cell Culture and Treatment Paradigm}

Under an intraperitoneal anesthesia with $1 \%$ pentobarbital sodium (50 mg/kg, Merck, USA, \#57-33-0), the embryos were removed from the uterus of 12-d pregnant ICR female mice. All treatments were in strict compliance with the guidelines of experimental animal center of Wenzhou Medical University and 
National Institute of Health Guide for Care and Use of Laboratory Animals (NIH Publications No.8023, revised 1978). The whole forebrain of embryo was quickly dissected from the skull.

Having removed the blood vessels, the LV-wall tissue from the forebrain was harvested, micro-dissected into $1 \times 1 \times 1 \mathrm{~mm}^{3}$ under a dissection microscope, digested with $0.05 \%$ trypsin/EDTA (Gibco Invitrogen, USA, \#59417C), triturated gently into the cell suspension and finally filtrated into a new centrifuged tube by the cell mesh with 400 -micro pores $(37.4 \mu \mathrm{m})$. The cell suspension was centrifuged at 1,000 rpm for 5 min and the supernatant was discarded. The cell pellets were resuspended with $500-\mu l$ Neurobasal proliferating medium (Gibco Invitrogen, \#21103049) supplemented with 10\% fetal bovine serum (FBS, Gibco Invitrogen, \#10100147C), 0.2\% basic fibroblast growth factor (bFGF, peprotech, USA, \#450 - 33) and 1\% GlutaMAX (Gibco Invitrogen, \#35050061) and then seeded to a 6- or 24-well plate at a density of 1 $x 10^{5}$ and kept at $37^{\circ} \mathrm{C}$ in $5 \% \mathrm{CO} 2$ incubator for $24 \mathrm{~h}$.

Once the neuro-spheres were formed, the cell medium was changed into the serum-free differentiation medium including 2\% B27 (Thermo Fisher Scientific, USA, \#17504044) and 1\% GlutaMAX. The siRNA expression plasmid targeting RBP-J (RBP-J-siRNA) was constructed by Santa Cruz Biotechnology Company (USA, \#sc-38215). On day 3 in vitro cell culture (DIV 3 ), the ependymal cells were divided into the control, Lipo2000, Control-siRNA (or empty vector) + lipo2000 and RBP-J-siRNA + lipo2000 groups.

The control group was referred as to the ependymal cells without any chemicals and reagents in the differentiation medium. In the RBP-J-siRNA + lipo2000 group, RBP-J-siRNA (10 pM) was mixed with lipo2000 (2:1; Thermo Fisher Scientific, \#11668030) at room temperature for $15 \mathrm{~min}$ and the mixture was added to $250-\mu \mathrm{l}$ cell medium and then continued to culture for $24 \mathrm{~h}$. In the control-siRNA + lipo2000 group, RBP-J-siRNA was replaced with the empty vector. On DIV 5, 7 and 10, the ependymal cells were attached onto poly-L-lysine-coated coverslips (Sigma-Aldrich, USA, \#P0425) and the immunofluorescent staining was performed.

\section{Mouse Breeding And Genotyping}

Three types of transgenic lines, namely CD133-CreER ${ }^{T M}$, ROSA26-LacZ and RBP-Jflox/flox mice, were obtained from Wenzhou Medical University. CD133-CreER ${ }^{T M}$ were crossed with ROSA26-LacZ mice and their offspring were then bred with RBP-Jflox/flox mice to obtain CD133-CreER ${ }^{T M}:: R O S A 26-L a c Z:: R B P$ Jlox/flox progeny (Han et al. 2002).

In order to detect the alleles, Taq Platinum PCR Master Mix (TianGen Biotech, China, \#4992790) was used along with PCR primers (Gibco Invitrogen) for genotyping ROSA (Fig. 3a; PCR product-300 bp: 5'-

AAAGTCGCTCTGAGTTGTTAT-3'; 5'-GCGAAGAGTTTGTCCTCAACC-3'), RBP-Jflox/flox (Fig. 3b; PCR product200 bp: 5'-TGCATAAAACCCCAGATGACTACC-3'; 5'-GCAATACCTTTCTGGGAGTTCTCT-3'; 5'GGGTAACCTTTGAGTTCTCTCAGT-3'), Cre (Fig. 3c; PCR product-300 bp: 5'-TCGATGCAACGAGTGATGAG3'; 5'-TCCATGAGTGAACGAACCTG-3') and CD133 (Fig. 3d; PCR product-586 bp for wild type or 320 bp for 
homozygote: 5'-CAGGCTGTTAGCTTGGGTTC-3'; 5'-TGCTGATTGCCTTCTGTCTG-3'; 5'AGGCAAATTTTGGTGTACGG-3').

The mice with the abovementioned four alleles were referred to as CD133-CreER ${ }^{T M}:: R O S A 26-L a c Z:: R B P$ flox/flox mice. CD133-driven Cre expression was present in CD133-positive ependymal cells, which were located in the SVZ and ependymal layer of LV, 3V and Aq (Coskun et al. 2008; Pfenninger et al. 2011; Luo et al. 2015). In order to inactivate RBP-J expression in CD133-positive ependymal cells, the adult CD133CreER $R^{T M}:: R O S A 26-L a c Z:: R B P$-Jflox/flox mice were intraperitoneally injected with $15 \mathrm{mg} / \mathrm{ml}$ of tamoxifen (TAM, $200 \sim 250 \mathrm{mg} / \mathrm{kg} / \mathrm{d}$; Sigma-Aldrich, \#T5648) or the same amount of corn oil (vehicle solution) for five consecutive days (Henry et al. 2009; Xie et al. 2017; Chen et al. 2020).

As a nonsteroidal antiestrogen, TAM was pre-dissolved in the corn oil to prepare a $75-\mathrm{mg} / \mathrm{ml}$ stock solution. The expression of TAM-induced Cre-recombinase was activated under CD133 promoters to excise both the transcriptional stop and RBP-J locus flanked by flox sites and induce the expression of $L a c Z$ gene in CD133-positive ependymal cells. The $\beta$-galactosidase ( $\beta$-Gal) that was encoded by LacZ gene can be detected by $\beta$-Gal immunofluorescent staining. Thus, $\beta$-Gal-positive cells were regarded as CD133-positive ependymal cells.

One day after the final intraperitoneal TAM treatment, four-month-old mice $(25 \sim 30 \mathrm{~g})$ were randomly assigned to the RBP-Jflox/flox-conditional knockout (RBP-JCKO mice) and control groups (CD133CreER ${ }^{T M}:: R O S A 26-L a c Z:: R B P-J^{-/-}$mice). Since the larger the sample size, the more possible in reflecting the true condition, meanwhile, we considered that it is hard to obtain the CD133-CreER $R^{T M}:: R O S A 26$ LacZ::RBP-Jflox/flox mice, each group had 6 mice in this study according to our previous published paper (Sun et al. 2012; Zhang et al. 2015; Xie et al. 2017; Chen et al. 2020).

Afterwards, the mice were sacrificed and then the immunofluorescent staining, Western blot and RT-qPCR were performed, as have been previously described (Sun et al. 2012; Zhang et al. 2015; Xie et al. 2017; Chen et al. 2020). During the experimental process, the RBP-J CKO and control groups of mice were housed in a standard environment with a controlled light/dark cycle, temperature and humidity. The mice can freely gain access to dry food pellets and water, in particular, their stress and pain should be reduced.

\section{Immunohistochemical And Immunocytochemical Staining}

For the immunocytochemical staining, the cells on the poly-L-lysine-coated coverslips in a 24-well plate were washed 3 times for 15 min with $0.01 \mathrm{M}$ phosphate-buffered saline (PBS, pH 7.4; Sigma-Aldrich, \#P3813) containing $0.1 \%$ Triton X-100 (Sigma-Aldrich, \#T8787) followed by a fixation in $4 \%$ cold paraformaldehyde (Sigma-Aldrich, \#158127)/PBS for $10 \mathrm{~min}$ at the room temperature. For the immunohistochemical staining, the RBP-J CKO and control group of mice were perfused intracardially with $0.85 \%$ normal saline (Merck, \#S0817) for 5 min followed by a fixative containing $4 \%$ cold paraformaldehyde in $0.1 \mathrm{M}$ phosphate buffer (PB, pH 7.4; Sigma-Aldrich, \#P5244) at the room 
temperature. The brain tissue was removed, post-fixed in the same fixative for $4 \mathrm{~h}$, and subsequently immersed in $30 \%$ sucrose solution (Merck, \#718033) overnight at $4^{\circ} \mathrm{C}$. The brain tissue was embedded in OCT tissue freezing medium (Merck, \#SHH0026).

Six sets of frozen serial coronal sections ( $40-\mu \mathrm{m}$ thick) were collected utilizing Leica cryostat (Germany) with $240-\mu \mathrm{m}$ distance at each set of consecutive sections. An antigen retrieval was performed in the antigen retrieval solution (10 mM trisodium citrate and $2 \mathrm{mM}$ citric acid, $\mathrm{pH}$ 6.0; Sigma-Aldrich, \#9999) for $6 \mathrm{~min}$ at $96^{\circ} \mathrm{C}$. In order to avoid a non-specific binding, the cells on the coverslips or the tissue frozen sections were subjected to the blocking solution containing $0.1 \%$ TritonX-100 (Thermo Fisher Scientific, \#9002-93-1) and 4\% normal serum (Abcam, USA) for 90 min at the room temperature followed by $3 \times 5$ min washes with $0.01 \mathrm{M}$ PBS.

In order to analyze the neuro-sphere formation of ependymal cells and their proliferation and differentiation, the primary antibody incubation was carried out overnight at $4^{\circ} \mathrm{C}$ in the specified dilution of blocking solution with the following primary antibodies: mouse anti-Nestin (marker for the NSCs, 1:400; Cell Signaling Technology or CST, USA, \#33475S), rabbit anti-proliferating cell nuclear antigen (PCNA, marker for the proliferating cells, 1:800; CST, \#2568), rabbit anti-doublecortin (DCX, marker for the immature neurons, 1:400; CST, \#148025), rabbit anti- $\beta$-tubulin III (marker for the immature neurons, 1:400; CST, \#151155), rat anti-CD133 (marker for the ependymal cells, 1:100; eBioscience, USA, \#14-1331-82), mouse anti-microtubule-associated protein 2 (MAP2, marker for the mature neuron, 1:400; Gibco Invitrogen, \#AB5622), mouse anti- $\beta$-Gal (maker for CD133-positive ependymal cells and their progeny, 1:3200; CST, \#14B7), rabbit anti-RBP-J (marker for a key integrator of Notch signaling pathway, 1:100; CST, \#720219), guinea pig anti-neuronal nuclear antigen (NeuN, marker for the mature neuron, 1:3000; Merck Millipore, USA, \#ABN90).

On the following day, the cells on the coverslips or the tissue sections were incubated with the appreciate host-specific secondary antibodies coupled to Alexa Fluor 594 goat-anti rabbit IgG (1:400; Jackson ImmunoResearch, USA, \#SAB4600322), Alexa Fluor 488 goat-anti rat IgG (1:400; Jackson ImmunoResearch, \#SAB4600235), DyLight ${ }^{\text {TM }} 594$ donkey-anti mice IgG (1:400; Jackson ImmunoResearch, \#SAB4600098) or DyLight ${ }^{\text {TM }} 488$ donkey-anti guinea pig IgG (1:400; Jackson ImmunoResearch, \#SAB4600033) at the room temperature for $90 \mathrm{~min}$. After $3 \times 5$ min washes with $0.01 \mathrm{M}$ PBS, the cells on the coverslips or the tissue sections were sealed by $75 \%$ glycerol mounting medium with or without 1 $\mathrm{mg} / \mathrm{ml}$ Hoechst (marker for the cell nuclei; Beyotime, China, \#HC08).

According to the previous published paper (Sun et al. 2012; Zhang et al. 2015; Xie et al. 2017; Wang et al. 2019; Chen et al. 2020), we have determined the targeted protein expressions in the cells and brain tissues. If the localization and expression of these proteins are expected, these antibodies are considered as to be specific. On the other hand, the appropriate immunoreactive controls were applied by replacing the primary antibodies with normal serum or $0.01 \mathrm{M}$ PBS and the results showed as negative.

\section{Rna Isolation And Real-time Qpcr Analysis}


According to Chen et al. (2020) report with the minor modifications, the total RNA (5 $\mu$ g) was extracted from the dissociated LV-wall tissue or cells using 1-ml Trizol reagent (Gibco Invitrogen, \#A33253) and the isolated RNA was treated with the DNase (Promega, USA, \#M6101). The CDNA templates were generated using the reverse transcription-PCR (RT-PCR, Gibco Invitrogen, \#C11730017) according to the manufacturer's instructions. The real-time quantitative PCR (qPCR, Gibco Invitrogen, \#CS11733038) for Notch1, RBP-J, Hes1 and $\beta$-actin was performed in $10 \mu$-reaction mixtures containing 1- $\mu$ l cDNA, 5- $\mu \mathrm{l} 2$ $\times$ TaqPCR MasterMix and 1- $\mu$ p primer. The expressions of related genes were subjected to 40 cycles of PCR amplification (PCR conditions: initial denaturation at $94^{\circ} \mathrm{C}$ for $30 \mathrm{sec}$; primer annealing at $60^{\circ} \mathrm{C}$ for $30 \mathrm{sec}$; primer extension at $60^{\circ} \mathrm{C}$ for $\left.1 \mathrm{~min}\right)$.

The following primers were used including Notch1 (forward primer: 5'TCGTGTGTCAAGCTGATGAGGA3'; reverse primer: 5'GTTCGGCAGCTACAGGTCACAA3'), RBP-J (forward primer: 5' GCCTGTTGTGACAGGGAAGTT 3'; reverse primer: 5' GATACACACAAGGAGGAGGGC 3'), Hes1 (forward primer: 5' CAACACGACACCGGACAAAC 3'; reverse primer: 5' GGAATGCCGGGAGCTATCTT 3') and $\beta$-actin (forward primer: 5' GCCTTCCTTCTTGGGTATGGAA 3'; reverse primer: 5' CAGCTCAGTAACAGTCCGCC').

The PCR products of Notch1, RBP-J and Hes1 were analyzed by $1.5 \%$ agarose gel electrophoresis (Gibco Invitrogen, $\# 16500500$ ) and quantified by $2-\triangle \Delta C T$ method using ChamQ SYBR qPCR Master Mix reagent (High ROX Premixed, China, \#Q311) and StepOne ${ }^{\mathrm{TM}}$ Software v2.1 (Thermo Fisher Scientific) according to the ratio between the cycle threshold $(C t)$ that the fluorescent signal crossed within the logarithmic phase of Notch1, RBP-J and Hes1 and that of the reference $\beta$-actin. The mRNA level of each sample was expressed as the percentage of control group. The real-time qPCR experiments were carried out by the six independent replicates.

\section{Protein Isolation And Western Blot Analysis}

The total protein was extracted according to the manufacture's instruction (Beyotime, \#AMJ-KT0007). Western blot has been previously described with a slight change (Wang et al. 2019; Chen et al. 2020). Briefly, the dissociated cells in a 6-well plate $\left(1 \times 10^{5}\right.$ /well) and the homogenized LV-wall tissue $(5 \mathrm{mg})$ were washed with the ice-cold 0.01 M PBS (pH 7.4), and then lysed in $200 \sim 250-\mu l$ radio immunoprecipitation assay (RIPA)/phenylmethanesulfonyl fluoride (PMSF) lysis buffer (100:1; Beyotime, \#36978) for $30 \mathrm{~min}$. The lysed cells and tissue were centrifuged at $12,000 \mathrm{rpm}$ for $20 \mathrm{~min}$ at $4^{\circ} \mathrm{C}$. The supernatants were collected, transferred to pre-chilled Eppendorf tube (total protein fraction), and then stored at $-80^{\circ} \mathrm{C}$ for further analysis.

The protein concentration was determined by BCA assay (Beyotime, \#P0010S). Forty micrograms of proteins that were isolated from the cells or brain tissues were loaded with $5 \mathrm{x}$ loading buffer containing $2 \%$ sodium dodecyl sulfate (SDS; Sigma-Aldrich, \#L4390) at $95^{\circ} \mathrm{C}$ water bath for $10 \mathrm{~min}$, run onto $10 \%$ SDS-polyacrylamide gel (PAGE; Merck, \#PCG2003) at 60 and $100 \mathrm{~V}$ successively for $1.5 \mathrm{~h}$. The protein band was cut out from PAGE according to a pre-stained marker (Thermo Fisher Scientific, \#PLU00464) 
and electro-transferred onto the polyvinylidene difluoride (PVDF) membrane (Merck, \#3010040001) at $300 \mathrm{~mA}$ for $1 \mathrm{~h}$.

Thereafter, the non-specific binding sites were blocked with 5\% non-fat milk in $50 \mathrm{mM}$ Tris-buffered saline and $0.1 \%$ Tween 20 (TBST, pH 7.5; Sigma-Aldrich, \#91414) at the room temperature for $2 \mathrm{~h}$. The membrane was incubated overnight at $4^{\circ} \mathrm{C}$ with the following specific primary antibodies containing rabbit anti-Notch 1 (CST, 1:1000,\#114-10200), rabbit anti-RBP-J (CST, 1:1000, \#720219), rabbit anti-Hes1 (CST, 1:1000, \#ab71559) and mouse anti- $\beta$-actin (domestic loading controls, 1:2000, Abgent, China, \#AF0003). Having washed for $3 \times 10$ min washes with $1 \times$ TBST, the membrane was incubated with the appropriate horseradish peroxidase (HRP)-conjugated goat anti-rabbit or mouse secondary antibody (1:5000, Jackson ImmunoResearch, \#111-035-003 or \#115-035-003) at the room temperature for $2 \mathrm{~h}$. The immuno-reactive protein band was detected with an enhanced chemiluminescent (ECL) kit (Beyotime, \#P0018FS). The protein level was normalized with respect to $\beta$-actin and the relative O.D. was calculated using an Image $\mathrm{J}$ software ( $\mathrm{NIH}$, Version 1.39x).

\section{Image Acquisition And Cell Counting}

According to the mouse brain atlas (Golmohammadi et al. 2008), a nonbiased stereological estimation was performed on every sixth serial brain section (240-um apart) throughout the rostro-caudal axis of brain. At the commencement of olfactory bulb, the first coronal brain section was collected. The number of $\beta$-Gal-, DCX-, $\beta$-tubulin III-, NeuN- and PCNA-immuno-positive cells was quantified in approximately 0.1$\mathrm{mm}$ area surrounding the $\operatorname{LV}(1.94,-2.92$ relative to the bregma), the third ventricle $(3 \mathrm{~V} ; 0.38,-2.80)$ and the cerebral aqueduct (Aq; -2.92, -5.02) from the randomly selected 16 frames with each measuring $30 \mu \mathrm{m} \times 30$ $\mu \mathrm{m}$ (Xie et al. 2017; Chen et al. 2020). The immuno-positive cells that fell inside the optical frame were counted via an optical fractionator (Q-imaging, Canada).

In the primarily cultured CD133-positive ependymal cells, the number of CD133-, DCX-, $\beta$-tubulin III-, MAP2and PCNA-immuno-positive cells was counted by the randomly selected 5 visual fields containing left, right, superior, central and inferior parts, and then expressed as the average value using an Image $J$ software.

The well-focused immuno-positive cells were captured under an upright fluorescent Olympus microscope equipped with a MicroFire CCD camera (Olympus Corporation, Japan). In order to identify the colocalization, the double immuno-positive cells were photographed in the three-dimensional (3D) reconstruction ( $x-y, x-z$, and $y-z$ planes) under a confocal laser scanning microscope (NIKON A1R, Japan), and then the confocal images were obtained along $Z$-axis with a 1- $\mu \mathrm{m}$ interslice gap.

During the experimental process, the brain sections were coded prior to the immuno-processing and cell counting. The observers who were blinded to the experimental conditions manifested these condes until all tasks have been completed. 


\section{Statistical Analysis}

The normality and variance homogeneity were assessed by applying Shapiro-Wilk normality test, Kolmogorov-Smirnov normality test and ordinary ANOVA test with Prism 8.0.1 software (GraphPad Software Incorporation, USA). All data were expressed as the mean \pm standard error mean (SEM) and statistically analyzed by ordinary one-way ANOVA with Tukey's test if the homoscedasticity was equal or Brown-Forsythe and Welch ANOVA tests with Dunnett's T3 test if the homoscedasticity was not equal for four groups, as well as unpaired two-tailed $t$ tests if both samples had the same SD or unpaired $t$ test with Welch's correction if the SDs were not equal, respectively. The results were considered to be statistically significant when the probability $(p)$ value was $\leq 0.05,0.01,0.001$ and 0.0001 .

\section{Results}

\section{Embryonic CD133-Positive Ependymal Cells Possessed the Characteristics of NSCs}

The SVZ and ependymal layer of LV-wall tissue were isolated, micro-dissected and dissociated into a single ependymal cell from the forebrain of embryonic day 12 (E12) mouse. Our results found that a very large percentage of cells $(94.63 \pm 2.09 \%)$ were CD133-positive ependymal cells when these cells were immunoreactive with CD133/Hoechst, revealing that CD133 was highly expressed in these primarily cultured ependymal cells (Fig. 1a).

Having been plated on the uncoated surfaces for $2 \sim 3$ days, most CD133-positive ependymal cells showed an oval or tadpole-like morphology with short processes. There was approximately $3 \sim 5$ neurospheres on the adherent surfaces at a low (Fig. 1c) or high magnification of visual field (Fig. 1d) and these neuro-spheres were immunoreactive with Nestin, demonstrating that CD133-positive ependymal cells possessed the properties of NSCs (Fig. 1e).

With the prolonged time in vitro primary culture, the soma of ependymal cells became much larger in diameter, meanwhile, their processes gradually grew ramifications vigorously and formed the neural networks. Having been seeded into the differentiation medium without bFGF, CD133-positive ependymal cells-derived neuro-spheres ultimately generated the bipolar or multipolar cells on DIV 9 (Fig. 1b).

RBP-J Interference Promoted the Proliferation and Differentiation of CD133-Positive Ependymal Cells in Vitro

To determine the effect of RBP-J inactivation on the neurogenesis of CD133-positive ependymal cells, CD133-positive ependymal cells were administrated with RBP-J-siRNA on DIV 3 and then were co-labelled with DCX, $\beta$-tubulin III, MAP2 and PCNA on DIV 5, 7 and 10. Our studies showed that CD133 was mainly enriched in the plasma membrane of ependymal cells and their projections. Under a fluorescent microscope, a cluster morphology-like DCX (Fig. 2a), as well as $\beta$-tubulin III (Fig. 2c) and MAP2 (Fig. 2e) 
were expressed in the prominent cytoplasm and neurite extension while PCNA was mainly present in the obvious nucleus (Fig. 2g).

As compared with the control, Lipo2000 and Control-siRNA + lipo2000 groups, RBP-J interference induced by RBP-J-siRNA significantly upregulated the ratio of CD133/DCX-(Fig. 2b; F(3.000, 16.64) =692.4, $W(3.000,10.90)=440.7, p<0.0001), C D 133 /$ MAP2- $($ Fig. 2f; $F(3.000,17.88)=559.8, W(3.000,10.97)=640.1$, $p<0.0001)$ and CD133/PCNA-double positive cells (Fig. 2h; $F(3.000,7.230)=344.1, W(3.000,9.773)=1952$, $p<0.0001)$ (Fig. 2i; $F(3.000,15.35)=691.4, W(3.000,10.74)=452.9, p<0.0001)$ (Fig. 2j; $F(3.000$, $17.38)=557.9, \mathrm{~W}(3.000,10.90)=525.2, p<0.0001)$ relative to the total CD133-positive ependymal cells, as well as the number of DCX- (Fig. $2 b ; F(3.000,14.50)=76.89, W(3.000,8.802)=63.53, p<0.0001)$, MAP2(Fig. 2f; $F(3.000,8.288)=9.721, p=0.0044 ; W(3.000,9.060)=201.4, p<0.0001)$ and PCNA-positive cells (Fig. $2 h ; F(3.000,14.45)=97.87, W(3.000,9.331)=70.24, p<0.0001)$ (Fig. 2i; $F(3.000,11.25)=77.57, W(3.000$, $10.20)=41.78, p<0.0001)$ (Fig. 2j; $F(3.000,12.99)=95.65, W(3.000,10.17)=54.79, p<0.0001)$ (normality and variance homogeneity, Brown-Forsythe and Welch ANOVA tests), except for the ratio of CD133/ $\beta$-tubulin III double-positive cells (Fig. $2 \mathrm{~d} ; \mathrm{F}(3,20)=2.683, p=0.0743$ ) or the number of $\beta$-tubulin III -positive cells (Fig. $2 \mathrm{~d} ; \mathrm{F}(3,20)=0.3696, p=0.7757)$ (normality and variance homogeneity, ordinary one-way ANOVA test) on DIV 5,7 and 10.

There was a significant decrease in CD133-positive ependymal cells of RBP-J-siRNA + lipo2000 groups (Fig. 2b; $F(3.000,10.36)=14.40, p<0.001 ; W(3.000,10.25)=53.47, p<0.0001)$ (Fig. 2f; $F(3.000$, $14.22)=4.237, p=0.0247 ; \mathrm{W}(3.000,8.480)=10.48, p=0.0032)$, as compared with the control, Lipo2000 and Control-siRNA+lipo2000 groups (normality and variance homogeneity, Brown-Forsythe and Welch ANOVA tests). However, no increase or decrease existed in the number of CD133-positive ependymal cells (Fig. 2d; $\mathrm{F}(3,20)=2.951, p=0.0575)$ (Fig. 2h; $\mathrm{F}(3,20)=1.509, p=0.2428)$ (Fig. 2i; $\mathrm{F}(3,20)=2.536, p=0.0857$ ) (Fig. 2j; $F(3,20)=0.7938, p=0.5116)$ (normality and variance homogeneity, ordinary one-way ANOVA test).

\section{RBP-J Was Expressed in CD133-Positive Ependymal Cells in Vivo}

To determine whether RBP-J was detected in CD133-positive ependymal cells, ROSA26-LacZ reporter mice were crossed with both $C D 133-C r e E R^{T M}$ and $R B P-J^{+/+}$or $R B P-J^{-/-}$mice. Since $\beta$-Gal-positive cell was regarded as an indicator of $C D 133$-positive ependymal cell and its downstream lineage, we performed an immunofluorescent staining for $\beta-G a l$. Our present results indicated that the immunoreactivity for $\beta$-Gal was exclusively localized in the SVZ or ependymal layer, as well as the vicinity of LV, $3 \mathrm{~V}$ and Aq, which was in accordance with the previous studies (Henry et al. 2009; Xie et al. 2017).

In CD133-CreER ${ }^{T M}:: R B P-J^{-/-}:: R O S A 26-L a c Z$ mice, RBP-J was expressed in the nuclear fraction of $\beta$-Galstained CD133-positive ependymal cells (Fig. 3e) after the mice have treated with TAM intraperitoneally for 5 consecutive days, moreover, approximately $90.26 \%$ of $\beta$-Gal-positive cells were co-expressed with RBP-J, revealing that RBP-J was active in the vast majority of CD133-positive ependymal cells. In contrast to the littermate controls, RBP-J expression was almost absent among the recombined cells of RBP-J CKO mice (Fig. 3f), leaving less than $5 \%$ of $\beta$-Gal-positive cells were co-labelled with RBP-J. These results indicated that RBP-J knockout was validated in CD133-positive ependymal cells of RBP-J CKO mice. 


\section{RBP-J Knockout Promoted the Proliferation and Differentiation of $\beta$-Gal-Labelled CD133-Positive Ependymal Cells in Vivo}

Since CD133-positive ependymal cells could be labelled with $\beta$-Gal, we examined $\beta$-Gal-positive cells with a variety of cell markers including PCNA, DCX or $\beta$-tubulin III and NeuN to determine the proliferation and differentiation of adult CD133-positive ependymal cells following a conditional ablation of RBP-J by a double immunofluorescent staining. The fluorescent microscope showed that $\beta$-Gal- (Fig. 4a, c, e and g; Fig. 5a h), DCX- (Fig. 4a, 5a, 5b), ß-tubulin III- (Fig. 4c, 5c, 5d) and PCNA-expressing cells (Fig. 4g, 5g, 5h) were prevalent in the regions surrounding LV-, 3V- and Aq-SVZ or ependymal layer. Interestingly, most NeuN-positive cells were seen to be away from the SVZ or ependymal layer into the adjacent parenchyma (Fig. 4e, 5e, 5f). The expression of $\beta$-Gal, DCX, $\beta$-tubulin III, NeuN and PCNA in vivo were in accordance with those of CD133, DCX, $\beta$-tubulin III, MAP2 and PCNA in vitro.

In the LV-, 3V- and Aq-SVZ or ependymal layer, our statistical results revealed that RBP-J ablation in CD133-positive ependymal cells resulted in a dramatic increase in the number of DCX- (Fig. 4b; $t(9.522)=$ $54.31, p<0.0001$ ) (Fig. 5a'; t(7.816)=7.019, $p<0.001$ ) (Fig. 5b'; $\mathrm{t}(6.782)=10.11, p<0.0001)$, $\beta$-tubulin III- (Fig. 4d; $\mathrm{t}(5.416)=14.45, p<0.0001)$ (Fig. 5c'; $\mathrm{t}(9.690)=5.696, p=0.0002)$ (Fig. 5d'; $\mathrm{t}(6.265)=29.22, p<0.0001)$, NeuN- (Fig. 4f; $\mathrm{t}(6.791)=5.230, p=0.0013)$ (Fig. 5e'; $\mathrm{t}(9.317)=14.14, p<0.0001)$ (Fig. 5f'; $\mathrm{t}(7.179)=8.935$, $p<0.0001)$ and PCNA-positive cells (Fig. 4h; $\mathrm{t}(6.085)=10.31, p<0.0001)$ (Fig. $5 g^{\prime} ; \mathrm{t}(6.214)=6.492, p<0.001$ ) (Fig. 5h'; $t(9.764)=3.933, p=0.0029)$, as compared with the control group (unpaired $t$ test with Welch's correction).

In comparison with the control group, RBP-JCKO mice had a significant increase in the fraction of $\beta$ Gal/DCX- (Fig. 4b; t(6.261) = 18.41, p<0.0001) (Fig. 5a'; t(8.482)=15.92, $p<0.0001$ ) (Fig. 5b'; $\mathrm{t}(9.779)=25.85, p<0.0001), \beta-G a l / \beta$-tubulin III- (Fig. 4d; t(5.606)=10.50, $p<0.0001)$ (Fig. 5c'; $\mathrm{t}(6.351)=10.27$, $p<0.0001$ ) (Fig. 5d'; t(6.565) =18.84, $p<0.0001), \beta-G a l / N e u N-(F i g .4 f ; t(9.282)=7.223, p<0.0001)$ (Fig. 5e'; $\mathrm{t}(5.061)=17.61, p<0.0001)$ (Fig. 5f'; $\mathrm{t}(7.682)=7.014, p<0.001)$ and $\beta$-Gal/PCNA-double positive cells (Fig. 4h; $\mathrm{t}(5.725)=20.65, p<0.0001)$ (Fig. 5g'; $\mathrm{t}(9.981)=17.91, p<0.0001)$ (Fig. 5h'; $\mathrm{t}(5.584)=13.34$, $p<0.0001)$ relative to $\beta$-Gal-positive cells (unpaired $t$ test with Welch's correction). Strikingly, our results showed that $\beta$-Gal-positive cells differentiation into the immature neurons (DCX and $\beta$-tubulin III) were much higher than the mature neurons $(\mathrm{NeuN})$, further confirming that RBP-J deletion easily made $\beta$-Galpositive cells differentiate into the immature rather than the mature neurons.

In addition, our results revealed that there was almost lack of an obvious alteration in the number of most $\beta$-Gal-positive cells of RBP-J CKO mice (Fig. 4b; $\mathrm{t}(10)=1.380, p=0.1976)$ (Fig. 4h; $\mathrm{t}(10)=0.6654, p=$ 0.5208) (Fig. 5a'; $\mathrm{t}(10)=0.3270, p=0.7504)$ (Fig. 5b'; $\mathrm{t}(10)=0.9825, p=0.3490)$ (Fig. 5c'; $\mathrm{t}(10)=0.4066, p$ $=0.6929)$ (Fig. 5e'; $\mathrm{t}(10)=2.143, p=0.0577)$ (Fig. 5g'; $\mathrm{t}(10)=1.857, p=0.0930)$ except for some increased $($ Fig. 4d; $\mathrm{t}(5.778)=7.203, p<0.001)($ Fig. 5d'; $\mathrm{t}(5.079)=5.882, p=0.0019)($ Fig. 5f'; $\mathrm{t}(5.332)=12.19, p<0.0001)$ (Fig. 5h'; $\mathrm{t}(6.132)=11.37, p<0.0001)$ or decreased $\beta$-Gal-positive cells (Fig. 4f; $\mathrm{t}(9.389)=4.336, p=0.0017$ ) (unpaired two-tailed $t$ tests and unpaired $t$ test with Welch's correction), which was in coincidence with those findings in the primarily cultured CD133-positive ependymal cells. 
RBP-J Interference or Knockout Regulated the RBP-J-, Notch1- and Hes1-mRNA Expressions in Vitro or in Vivo

Notch1 is an upstream component that binds RBP-J while Hes 1 is a downstream target that represses the expression of pro-neural genes, thus we examined whether the expression levels of Notch1- and Hes1mRNA were altered following RBP-J inactivation in vitro and in vivo using real-time qPCR. As compared with the control, Lipo2000 and Control-siRNA + lipo2000 groups in the primarily cultured CD133-positive ependymal cells, our results indicated that the relative expression level of RBP-J-mRNA was significantly decreased following RBP-J interference (Fig. 6a; $F(3.000,14.76)=3507, W(3.000,10.14)=5032$, $p<0.0001$ ) (normality and variance homogeneity, Brown-Forsythe and Welch ANOVA tests). RBP-J knockout in CD133-positive ependymal cells also significantly decreased RBP-J mRNA expression level in the LV-wall tissue to about $85.18 \sim 91.5 \%$ of the control group (Fig. $6 \mathrm{~g} ; \mathrm{t}(9.644)=36.82, p<0.0001$ ) (unpaired $t$ test with Welch's correction), indicating that TAM-induced Cre-expression resulted in an efficient recombination of RBP-J.

Meanwhile, the relative expression level in RBP-J-siRNA + lipo2000 group of primarily cultured CD133positive ependymal cells or RBP-J CKO mice had a significant increase in Notch1-mRNA (Fig. 6b: $\mathrm{F}$ (3.000, $5.690)=194.4, \mathrm{~W}(3.000,10.64)=61.01, p<0.0001$; Fig. 6h: $\mathrm{t}(5.008)=13.77, p<0.0001)$ and decrease in Hes1-mRNA (Fig. 6c: $\mathrm{F}(3.000,16.50)=149.5$, W(3.000, 10.59) =117.4, $p<0.0001$ ); Fig. 6i: $\mathrm{t}(5.480)=48.17$, $p<0.0001)$ (Brown-Forsythe and Welch ANOVA tests and unpaired $t$ test with Welch's correction). These results demonstrated that RBP-J deletion could upregulate and downregulate the relative expression levels of Notch1- and Hes1-mRNA, respectively.

\section{RBP-J Interference or Knockout Regulated the RBP-J, Notch1 and Hes1 Protein Expressions in Vitro or in Vivo}

Additionally, we examined the expression levels of RBP-J, Notch1 and Hes1 proteins using Western blot in order to further confirm whether these protein expressions were in accordance with their mRNA levels. Consistent with RBP-J-mRNA, the decreased relative expression level of RBP-J protein was more evident following RBP-J interference, as compared to the control, Lipo2000 and Control-siRNA + lipo2000 groups in the primarily cultured CD133-positive ependymal cells (Fig. 6d; $F(3.000,18.22)=2363, W(3.000,10.83)$ $=1861, p<0.0001)$ (normality and variance homogeneity, Brown-Forsythe and Welch ANOVA tests). Furthermore, RBP-J knockout in CD133-positive ependymal cells abruptly decreased RBP-J protein expression level in the LV-wall tissue to about $69.03 \sim 71.71 \%$ of the control group (Fig. $6 \mathrm{j} ; \mathrm{t}(5.233)=46.66$, $p<0.0001$ ) (unpaired $t$ test with Welch's correction).

Our results demonstrated that the relative expression levels following RBP-J siRNA or knockout had a significant increase in Notch1 protein (Fig. 6e: $F(3.000,16.81)=489.7, W(3.000,10.83)=338.3, p<0.0001$; Fig. $6 \mathrm{k}: \mathrm{t}(6.493)=24.23, p<0.0001)$ and an obvious reduction in Hes1 protein (Fig. $6 \mathrm{f:} F(3.000$, 13.14) $=720.0, \mathrm{~W}(3.000,9.911)=1715, p<0.0001$; Fig. $6 \mathrm{l}: \mathrm{t}(5.472)=22.84, p<0.0001)$, which was in accordance with their mRNA expression levels. Taken together, our results suggested that Notch1 and Hes 1 were specifically upregulated and downregulated in the absence of RBP-J by the transcriptional and 
translational mechanisms, which might account for RBP-J deletion-induced the proliferation and differentiation of CD133-positive ependymal cells.

\section{Discussion}

It has been widely accepted that the LV-SVZ-NPCs or NSCs had a neurogenic capacity, so they could transiently amplify, migrate into the damaged brain areas and differentiate into the neuroblasts once activated (Doetsch et al. 2002; Carlen et al. 2009). In the LV-SVZ, four types of cells have been characterized as the identities of NSCs, which are referred to as the neuroblast A cells, subependymal astrocyte $B$ cells, transit-amplifying immature precursor $C$ cells and ependymal $E$ cells (Doetsch et al. 1997; Beckervordersandforth et al. 2010).

During the activation of NSC, B cells produce $C$ cells that give rise to a large number of $A$ cells (Doetsch 2003; Luo et al. 2015). A large amount of published literature revealed that the NSCs residing in the forebrain LV-SVZ neurogenic niche of the adult mouse could maintain a homeostasis between the quiescent state and neurogenesis throughout the lifetime (Doetsch 2003; Merkle et al. 2007; Coskun et al. 2008; Morrison and Spradling 2008; Beckervordersandforth et al. 2010; Li and Clevers 2010; Lugert et al. 2010; Ming and Song 2011).

Several studies have demonstrated that the ependymal E cells residing in the LV-wall tissue display the properties of NSCs, because they are in close proximity to the LV-SVZ (Johansson et al. 1999; Coskun et al. 2008; Nakafuku et al. 2008). Our findings indicated that the primarily embryonic cultured CD133positive ependymal cells possessed the capacity of forming the neuro-spheres, which was in agreement with in vivo studies that CD133-positive ependymal cells could differentiate and give rise to neurons, although it has been debated about the contribution of ependymal E cells to the lineage of postnatal SVZ (Reya et al. 2001; Singh et al. 2004; Spassky et al. 2005; Coskun et al. 2008; Carlen et al. 2009; Chojnacki et al. 2009; Luo et al. 2015).

Some studies suggested that the ependymal E cells were structural cells and could not serve as the NSCs (Chiasson et al. 1999; Doetsch et al. 1999; Capela and Temple 2002). According to our presented protocol, the isolated embryonic CD133-positive ependymal cells gave rise to the immature or mature neurons, which expressed DCX, $\beta$-tubulin III or MAP2 in vitro. Since CD133-positive ependymal cells had a proliferative and differentiated potential, they could be consumed in the process of generating the progeny, thus serving as a reservoir of NSCs (Horner et al. 2000; Nagao et al. 2007; Coskun et al. 2008; Meletis et al. 2008; Carlen et al. 2009; Barnabe-Heider et al. 2010; Alfaro-Cervello et al. 2012).

Our study demonstrated that CD133-positive ependymal cells were greatly reduced when they differentiated into the DCX- and MAP2-postive cell following the inactivation of RBP-J. Nevertheless, we also noticed that the number of CD133-positive ependymal cells was unchanged when they were stained with the proliferative marker PCNA, indicating that CD133-positive ependymal cells in a proliferative state immediately differentiated into the immature and mature neurons. These results suggested that it was

Page $14 / 36$ 
essential to ensure a balance between the maintenance of CD133-positive ependymal cells and their neurogenesis.

Some reports proposed that CD133-expressing ependymal cells in the SVZ and ependymal layer of mammalian forebrain rendered a quiescent NSC population under physiological conditions (Doetsch et al. 1999; Capela and Temple 2002; Spassky et al. 2005; Coskun et al. 2008). In response to exposure to the vascular endothelial growth factor (VEGF) and bFGF, CD133-positive ependymal cells are recruited, mitotically activated and then driven into the neurogenesis (Carlen et al. 2009; Luo et al. 2015; Kitada et al. 2018).

Pfenninger et al. (2011) reported that the administration of VEGF was capable of activating CD133positive ependymal cells lining not only the LV but also the fourth ventricle, as well as eliciting their subsequent migration and differentiation. It was worth noting that our studies in the adult mice indicated that the prominin-1-gene-encoding CD133-positive ependymal cells were also located in the 3V-and AqSVZ and ependymal layer except for the LV.

Many studies have shown that the ependymal cells migrate away from the ependymal layer toward the dorsal part of the spinal cord following the neural injury, where they differentiate into the glial cells (Johansson et al. 1999; Mothe and Tator 2005; Kitada et al. 2018). By constructing a recombinant plasmid prominin-1-mP2-driven Cre, our studies revealed that the progeny of CD133-positive ependymal cells gradually migrated toward the surrounding parenchyma from the 3V-and Aq-ependymal layer following an intranigral injection of 6-OHDA (Xie et al. 2017). These findings indicated that the ependymal cells have a migratory activity over the boundary between the ependymal layer and parenchyma.

Although the neurogenesis of adult NPCs is involved in the self-repair processes and provides a prospect to restore the lost neurons in a complementary pattern, the newly generated neuroblasts are poor survival in an unfavorable microenvironment (Weill-Engerer et al. 2002; Hattiangady and Shetty 2008; Carlen et al. 2009; Cave et al. 2014). In addition, a substantial loss of ependymal cells appeared to be unable to selfrenew sufficiently to maintain their own population during the regeneration following the stroke (Carlen et al. 2009).

Shi et al. (2012) and Kitada et al. (2018) have demonstrated that the intracellular abundant signals of ependymal cells are similar to those of NSCs. Moreover, many signal transduction pathways are required for the neurogenesis of ependymal cells in the adult mouse brain (Zhao et al. 2003; Höglinger et al. 2004; Shan et al. 2006; Zhao and Janson 2009; Berg et al. 2011; Peng and Andersen 2011). As mentioned in many studies, Notch/RBP-J signaling pathway is known to contribute to the adult NSCs maintenance and their self-renewal (Tanigaki et al. 2001; Hitoshi et al. 2002; Chojnacki et al. 2003; Takizawa et al. 2003; Duncan et al. 2005; Nagao et al. 2007; Shimizu et al. 2008).

Some studies have shown that a soluble Notch ligand infusion into the niche of LV-wall tissue could promote the proliferation of NPCs and their migration into the parenchyma (Androutsellis-Theotokis et al. 2006; Carlen et al. 2009). Carlen et al. (2009) reported that Notch signaling may maintain the ependymal 
cells of forebrain in a quiescent state following a stroke. Ki67-positve proliferating cells that were originated from the progeny of ependymal cells were observed in close proximity of the ependymal layer after NICD gene was introduced into the ependymal cells (Andreu-Agullo et al. 2009; Ehm et al. 2010; Kitada et al. 2018).

By using the transgenic mice, our present study found that a nearly $90 \%$ of $\beta$-Gal-positive cells were co-

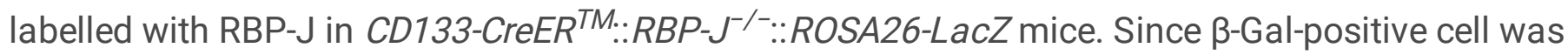
regarded as an indicator of CD133-positive ependymal cell, our results indicated that RBP-J expression was enriched in CD133-positive ependymal cells of adult mouse LV-wall tissue. The phenotype of RBP-JCKO was the consequence of RBP-J deficiency.

In absent of Notch receptor or NICD, RBP-J is bound to a repressor complex to promote the differentiation of NSCs (Bertrand et al. 2002; Han et al. 2002; Baron M 2003; Bray 2006; Imayoshi et al. 2008). Either the ablation or inhibition of RBP-J promotes the premature neuronal differentiation, leading to the depletion of NPCs or NSCs (Yoon and Gaiano 2005; Louvi and Artavanis-Tsakonas 2006). However, our results demonstrated that although the differentiation of $\beta$-Gal-positive cells was increased, the number of $\beta-G a l-$ positive cells was also increased or kept constant when RBP-J was interfered. It was likely that an increasing fraction in the double-positive cells of RBP-J CKO mice was not completely caused by the recombined $\beta$-Gal-positive cells. We cannot fully exclude that the non-recombined cells might be recruited into the proliferation and differentiation and at least in part functionally compensate for RBP-J loss (Androutsellis-Theotokis et al. 2006). In addition, a different recombination efficiency of $\beta$-Gal-positive cells might contribute to the conflicting results in RBP-J-CKO mice.

A report has proved that RBP-J inactivation increases the neurogenesis of CD133-positive ependymal cells, since RBP-J becomes an inhibitor in the differentiation of CD133-positive ependymal cells (Lie et al. 2004). Our study indicated that an increased trend in the ratio of $\beta$-gal/ $\beta$-tubulin III was observed in RBP-JCKO, while it was not the case in the primarily cultured CD133-positive ependymal cells. An alternative interpretation is that CD133-positive cells consist of the NSCs, NPCs and immature neurons at the embryonic stage, which are stained with the $\beta$-tubulin III, thus RBP-J deletion hardly affects the ratio of $\beta$ gal/ $\beta$-tubulin III in vitro.

Because Hes1 is regulated by its upstream RBP-J, a drastic downregulation in Hes1-mRNA and its protein was observed in the absence of RBP-J. RBP-J deletion inhibits the expression of transcription factor Hes1, and finally promotes the neuronal differentiation (Kageyama and Ohtsuka 1999; Machold and Fishell 2005). A group of studies have revealed that Notch/RBP-J maintains the quiescence of radial glia-like NSCs by controlling the expression of Hes (Ohsawa et al. 2005; Louvi and Artavanis-Tsakonas 2006). Another report indicated that RBP-J inactivation could not maintain the adult SVZ-derived NSCs in a pluripotent state, leading to a phenotype of neurogenesis (Yoon and Gaiano 2005; Imayoshi et al. 2010).

Our results suggested that RBP-J deletion displayed a dramatically enhanced neurogenesis of CD133positive ependymal cells, which might be attributable to RBP-J deletion-induced a depression effect on the expression of Hes1. Androutsellis-Theotokis et al. (2006) reported that RBP-J-dependent Notch 
signaling promoted the proliferation of NSCs in the adult mouse brain, however, our results indicated that RBP-J deficiency induced an increase in the proliferation of $\beta$-Gal-labelled CD133-positive ependymal cells when the $\beta$-Gal cells were stained with PCNA.

As showed in our research results, the expression of Notch1-mRNA and its protein was upregulated following RBP-J disruption, which was likely to be due to the rescue of Notch1 consumption since NICDRBP-J complex failed to be formed. Some studies reported that the forced Notch1 signaling led to a transient increase in the proliferation of hippocampal NSCs, whereas Notch1 ablation promoted the exit of cell cycle and the neuronal differentiation (Breunig et al. 2007; Ables et al. 2010), which was in accordance with our study that the upregulated Notch1 expression can induce an increase in the proliferation of CD133-positive ependymal cells.

However, we also cannot fully exclude the possibility that these proliferative CD133-positive ependymal cells might be mediated through an intact RBP-J-independent Notch signaling pathways, because RBP-Jindependent pathway was intact in RBP-J-CKO mice (Androutsellis-Theotokis et al. 2006), but it is fully uncovered about its detailed mechanisms.

\section{Conclusions}

Taken together, our data have reached the conclusion that RBP-J ablation may be implicated in the neurogenesis of CD133-positive ependymal cells by inducing a downregulation in Hes1 and an upregulation in Notch1 expression. These findings indicate that RBP-J-dependent Notch signaling pathway is essential for the balance between the maintenance of CD133-positive ependymal cells and their differentiation within the SVZ of ventricles. Our study provides a novel molecular insight into the function of RBP-J, as well as facilitates a future investigation of CD133-positive ependymal cells with respect to their potential application in Parkinson disease.

\section{Declarations}

\section{Funding}

This work was supported by the National Natural Science Foundation of China $(82171577,81671401)$ and Wenzhou Public Welfare Science and Technology Project of China (Y20190059).

\section{Compliance with Ethical Standards}

All authors have agreed to publish this paper and declare no conflict of interest. This paper does not contain any studies with human participants.

\section{Authorship Contribution Statement}

Chenyou Sun: Being full access to all the data in the study and the integrity and the accuracy of the data analysis. Min Liao: Study design. Xin Ye, Mengyi Li and Wei Bian: Data collection. Peng Zhou, Junwei Li 
and Ting Zhang: Data analysis and interpretation. Huairui Cui, Yu-Qiang Ding and Shuangshuang Qi: Drafting manuscript. Anting Wu: Manuscript preparation.

\section{Data Availability Statement}

All data in this paper will be made available upon publication.

\section{References}

1. Ables JL, Decarolis NA, Johnson MA, Rivera PD, Gao Z, Cooper DC, Radtke F, Hsieh J, Eisch AJ (2010) Notch1 is required for maintenance of the reservoir of adult hippocampal stem cells. J Neurosci 30(31):10484-10492. https://doi.org/10.1523/JNEUROSCI.4721-09.2010

2. Alfaro-Cervello C, Soriano-Navarro M, Mirzadeh Z, Alvarez-Buylla A, Garcia-Verdugo JM (2012) Biciliated ependymal cell proliferation contributes to spinal cord growth. J Comp Neurol 520(15):3528-3552. https://doi.org/10.1002/cne.23104

3. Andreu-Agullo C, Morante-Redolat JM, Delgado AC, Farinas I (2009) Vascular niche factor PEDF modulates Notch-dependent stemness in the adult subependymal zone. Nat Neurosci 12(12):15141523. https://doi.org/10.1038/nn.2437

4. Androutsellis-Theotokis A, Leker RR, Soldner F, Hoeppner DJ, Ravin R, Poser SW, Rueger MA, Bae SK, Kittappa R, McKay RD (2006) Notch signalling regulates stem cell numbers in vitro and in vivo. Nature 442(7104):823-826. https://doi.org/10.1038/nature04940

5. Barnabé-Heider F, Göritz C, Sabelström H, Takebayashi H, Pfrieger FW, Meletis K, Frisén J (2010) Origin of new glial cells in intact and injured adult spinal cord. Cell Stem Cell 7(4):470-482. https://doi.org/10.1016/j.stem.2010.07.014

6. Baron M (2003) An overview of the Notch signalling pathway. Semin Cell Dev Biol 14:113-119. https://doi.org/10.1016/s1084-9521(02)00179-9

7. Basak 0 , Taylor $V$ (2007) Identification of self-replicating multipotent progenitors in the embryonic nervous system by high Notch activity and Hes5 expression. Eur J Neurosci 25(4):1006-1022. https://doi.org/10.1111/j.1460-9568.2007.05370.x

8. Beckervordersandforth R, Tripathi P, Ninkovic J, Bayam E, Lepier A, Stempfhuber B, Kirchhoff F, Hirrlinger J, Haslinger A, Lie DC, Beckers J, Yoder B, Irmler M, Gotz M (2010) In vivo fate mapping and expression analysis reveals molecular hallmarks of prospectively isolated adult neural stem cells. Cell Stem Cell 7(6):744-758. https://doi.org/10.1016/j.stem.2010.11.017

9. Berg DA, Kirkham M, Wang H, Frisen J, Simon A (2011) Dopamine controls neurogenesis in the adult salamander midbrain in homeostasis and during regeneration of dopamine neurons. Cell Stem Cell 8(4):426-433. https://doi.org/10.1016/j.stem.2011.02.001

10. Bertrand N, Castro DS, Guillemot F (2002) Proneural genes and the specification of neural cell types. Nat Rev Neurosci 3(7):517-530. https://doi.org/10.1038/nrn874 
11. Blanpain C, Lowry WE, Pasolli HA, Fuchs E (2006) Canonical notch signaling functions as a commitment switch in the epidermal lineage. Genes Dev 20(21):3022-3035. https://doi.org/10.1101/gad.1477606

12. Bray SJ (2006) Notch signalling: a simple pathway becomes complex. Nat Rev Mol Cell Biol 7(9):678-689. https://doi.org/10.1038/nrm2009

13. Breunig JJ, Silbereis J, Vaccarino FM, Sestan N, Rakic P (2007) Notch regulates cell fate and dendrite morphology of newborn neurons in the postnatal dentate gyrus. Proc Natl Acad Sci U S A 104(51):20558-20563. https://doi.org/10.1073/pnas.0710156104

14. Capela A, Temple S (2002) LeX/ssea-1 is expressed by adult mouse CNS stem cells, identifying them as nonependymal. Neuron 35(5):865-875. https://doi.org/10.1016/s0896-6273(02)00835-8

15. Carlen M, Meletis K, Goritz C, Darsalia V, Evergren E, Tanigaki K, Amendola M, Barnabe-Heider F, Yeung MS, Naldini L, Honjo T, Kokaia Z, Shupliakov O, Cassidy RM, Lindvall O, Frisen J (2009) Forebrain ependymal cells are Notch-dependent and generate neuroblasts and astrocytes after stroke. Nat Neurosci 12(3):259-267. https://doi.org/10.1038/nn.2268

16. Cave JW, Wang M, Baker H (2014) Adult subventricular zone neural stem cells as a potential source of dopaminergic replacement neurons. Front Neurosci 8:16.

https://doi.org/10.3389/fnins.2014.00016

17. Chen ZC, Wang TT, Bian W, Ye X, Li MY, Du JJ, Zhou P, Cui HR, Ding YQ, Ren YH, Qi SS, Yuan YY, Liao $M$, Sun CY (2020) Allopregnanolone restores the tyrosine hydroxylase-positive neurons and motor performance in a 6-OHDA-injected mouse model. CNS Neurosci Ther 26(10):1069-1082. https://doi.org/10.1111/cns.13432

18. Chiasson BJ, Tropepe V, Morshead CM, van der Kooy D (1999) Adult mammalian forebrain ependymal and subependymal cells demonstrate proliferative potential, but only subependymal cells have neural stem cell characteristics. J Neurosci 19(11):4462-4471.

https://doi.org/10.1523/JNEUROSCl.19-11-04462.1999

19. Chojnacki A, Shimazaki T, Gregg C, Weinmaster G, Weiss S (2003) Glycoprotein 130 signaling regulates Notch1 expression and activation in the self-renewal of mammalian forebrain neural stem cells. J Neurosci 23(5):1730-1741. https://doi.org/10.1523/JNEUROSCI.23-05-01730.2003

20. Chojnacki AK, Mak GK, Weiss S (2009) Identity crisis for adult periventricular neural stem cells: subventricular zone astrocytes, ependymal cells or both? Nat Rev Neurosci 10(2):153-163. https://doi.org/10.1038/nrn2571

21. Codega P, Silva-Vargas V, Paul A, Maldonado-Soto AR, Deleo AM, Pastrana E, Doetsch F (2014) Prospective identification and purification of quiescent adult neural stem cells from their in vivo niche. Neuron 82(3):545-559. https://doi.org/10.1016/j.neuron.2014.02.039

22. Coskun V, Wu H, Blanchi B, Tsao S, Kim K, Zhao J, Biancotti JC, Hutnick L, Krueger RJ, Fan G, de Vellis J, Sun YE (2008) CD133 + neural stem cells in the ependyma of mammalian postnatal forebrain. Proc Natl Acad Sci U S A 105(3):1026-1031. https://doi.org/10.1073/pnas.0710000105 
23. Doetsch F (2003) The glial identity of neural stem cells. Nat Neurosci 6:1127-1134. https://doi.org/10.1038/nn1144

24. Doetsch F, Caillé I, Lim DA, García-Verdugo JM, Alvarez-Buylla A (1999) Subventricular zone astrocytes are neural stem cells in the adult mammalian brain. Cell 97(6):703-716. https://doi.org/10.1016/s0092-8674(00)80783-7

25. Doetsch F, Garcia-Verdugo JM, Alvarez-Buylla A (1997) Cellular composition and three-dimensional organization of the subventricular germinal zone in the adult mammalian brain. J Neurosci 17(13):5046-5061. https://doi.org/10.1523/JNEUROSCI.17-13-05046.1997

26. Doetsch F, Petreanu L, Caille I, Garcia-Verdugo JM, Alvarez-Buylla A (2002) EGF converts transitamplifying neurogenic precursors in the adult brain into multipotent stem cells. Neuron 36(6):10211034. https://doi.org/10.1016/s0896-6273(02)01133-9

27. Duncan AW, Rattis FM, DiMascio LN, Congdon KL, Pazianos G, Zhao C, Yoon K, Cook JM, Willert K, Gaiano N, Reya T (2005) Integration of Notch and Wnt signaling in hematopoietic stem cell maintenance. Nat Immunol 6(3):314-322. https://doi.org/10.1038/ni1164

28. Ehm O, Goritz C, Covic M, Schaffner I, Schwarz TJ, Karaca E, Kempkes B, Kremmer E, Pfrieger FW, Espinosa L, Bigas A, Giachino C, Taylor V, Frisen J, Lie DC (2010) RBPJkappa-dependent signaling is essential for long-term maintenance of neural stem cells in the adult hippocampus. J Neurosci 30(41):13794-13807. https://doi.org/10.1523/JNEUROSCI.1567-10.2010

29. Fargeas CA, Corbeil D, Huttner WB (2003) AC133 antigen, CD133, prominin-1, prominin-2, etc.: prominin family gene products in need of a rational nomenclature. Stem Cells 21(4):506-508. https://doi.org/10.1634/stemcells.21-4-506

30. Furukawa T, Mukherjee S, Bao ZZ, Morrow EM, Cepko CL (2000) rax, Hes1, and notch1 promote the formation of Muller glia by postnatal retinal progenitor cells. Neuron 26(2):383-394. https://doi.org/10.1016/s0896-6273(00)81171-x

31. Golmohammadi MG, Blackmore DG, Large B, Azari H, Esfandiary E, Paxinos G, Franklin KB, Reynolds BA, Rietze RL (2008) Comparative analysis of the frequency and distribution of stem and progenitor cells in the adult mouse brain. Stem Cells 26(4):979-987. https://doi.org/10.1634/stemcells.20070919

32. Grospe GM, Baker PM, Ragozzino ME (2018) Cognitive flexibility deficits following 6-OHDA lesions of the rat dorsomedial striatum. Neuroscience 374:80-90. https://doi.org/10.1016/j.neuroscience.2018.01.032

33. Han H, Tanigaki K, Yamamoto N, Kuroda K, Yoshimoto M, Nakahata T, Ikuta K, Honjo T (2002) Inducible gene knockout of transcription factor recombination signal binding protein-J reveals its essential role in T versus B lineage decision. Int Immunol 14(6):637-645. https://doi.org/10.1093/intimm/dxf030

34. Hattiangady B, Shetty AK (2008) Aging does not alter the number or phenotype of putative stem/progenitor cells in the neurogenic region of the hippocampus. Neurobiol Aging 29(1):129-147. https://doi.org/10.1016/j.neurobiolaging.2006.09.015 
35. Henry SP, Jang C, Deng JM, Zhang Z, Behringer RR, de Crombrugghe B (2009) Generation of aggrecan-CreERT2 knockin mice for inducible Cre activity in adult cartilage. Genesis 47(12):805-814. https://doi.org/10.1002/dvg.20564

36. Hitoshi S, Alexson T, Tropepe V, Donoviel D, Elia AJ, Nye JS, Conlon RA, Mak TW, Bernstein A, van der Kooy D (2002) Notch pathway molecules are essential for the maintenance, but not the generation, of mammalian neural stem cells. Genes Dev 16(7):846-858. https://doi.org/10.1101/gad.975202

37. Höglinger GU, Rizk P, Muriel MP, Duyckaerts C, Oertel WH, Caille I, Hirsch EC (2004) Dopamine depletion impairs precursor cell proliferation in Parkinson disease. Nat Neurosci 7(7):726-735. https://doi.org/10.1038/nn1265

38. Horner PJ, Power AE, Kempermann G, Kuhn HG, Palmer TD, Winkler J, Thal LJ, Gage FH (2000) Proliferation and differentiation of progenitor cells throughout the intact adult rat spinal cord. $J$ Neurosci 20(6):2218-2228. https://doi.org/10.1523/JNEUROSCI.20-06-02218.2000

39. Imayoshi I, Sakamoto M, Yamaguchi M, Mori K, Kageyama R (2010) Essential roles of Notch signaling in maintenance of neural stem cells in developing and adult brains. J Neurosci 30(9):3489-3498. https://doi.org/10.1523/JNEUROSCI.4987-09.2010

40. Imayoshi I, Shimogori T, Ohtsuka T, Kageyama R (2008) Hes genes and neurogenin regulate nonneural versus neural fate specification in the dorsal telencephalic midline. Development 135(15):2531-2541. https://doi.org/10.1242/dev.021535

41. Johansson CB, Momma S, Clarke DL, Risling M, Lendahl U, Frisen J (1999) Identification of a neural stem cell in the adult mammalian central nervous system. Cell 96(1):25-34. https://doi.org/10.1016/s0092-8674(00)80956-3

42. Kageyama R, Ohtsuka T (1999) The Notch-Hes pathway in mammalian neural development. Cell Res 9(3):179-188. https://doi.org/10.1038/sj.cr.7290016

43. Kitada M, Wakao S, Dezawa M (2018) Intracellular signaling similarity reveals neural stem cell-like properties of ependymal cells in the adult rat spinal cord. Dev Growth Differ 60(6):326-340. https://doi.org/10.1111/dgd.12546

44. Li L, Clevers H (2010) Coexistence of quiescent and active adult stem cells in mammals. Science 327(5965):542-545. https://doi.org/10.1126/science.1180794

45. Lee A, Kessler JD, Read TA, Kaiser C, Corbeil D, Huttner WB, Johnson JE, Wechsler-Reya RJ (2005) Isolation of neural stem cells from the postnatal cerebellum. Nat Neurosci 8(6):723-729. https://doi.org/10.1038/nn1473

46. Lie DC, Song H, Colamarino SA, Ming GL, Gage FH (2004) Neurogenesis in the adult brain: new strategies for central nervous system diseases. Annu Rev Pharmacol Toxicol 44:399-421. https://doi.org/10.1146/annurev.pharmtox.44.101802.121631

47. Louvi A, Artavanis-Tsakonas S (2006) Notch signalling in vertebrate neural development. Nat Rev Neurosci 7(2):93-102. https://doi.org/10.1038/nrn1847

48. Lugert S, Basak O, Knuckles P, Haussler U, Fabel K, Gotz M, Haas CA, Kempermann G, Taylor V, Giachino C (2010) Quiescent and active hippocampal neural stem cells with distinct morphologies 
respond selectively to physiological and pathological stimuli and aging. Cell Stem Cell 6(5):445-456. https://doi.org/10.1016/j.stem.2010.03.017

49. Luo Y, Coskun V, Liang A, Yu J, Cheng L, Ge W, Shi Z, Zhang K, Li C, Cui Y, Lin H, Luo D, Wang J, Lin C, Dai Z, Zhu H, Zhang J, Liu J, Liu H, DeVellis J, Horvath S, Sun YE, Li S (2015) Single-cell transcriptome analyses reveal signals to activate dormant neural stem cells. Cell 161(5):1175-1186. https://doi.org/10.1016/j.cell.2015.04.001

50. Machold R, Fishell G (2005) Math1 is expressed in temporally discrete pools of cerebellar rhombic-lip neural progenitors. Neuron 48(1):17-24. https://doi.org/10.1016/j.neuron.2005.08.028

51. Marzesco AM, Janich P, Wilsch-Brauninger M, Dubreuil V, Langenfeld K, Corbeil D, Huttner WB (2005) Release of extracellular membrane particles carrying the stem cell marker prominin-1 (CD133) from neural progenitors and other epithelial cells. J Cell Sci 118(Pt 13):2849-2858. https://doi.org/10.1242/jcs.02439

52. Meletis K, Barnabe-Heider F, Carlen M, Evergren E, Tomilin N, Shupliakov O, Frisen J (2008) Spinal cord injury reveals multilineage differentiation of ependymal cells. Plos Biol 6(7):e182. https://doi.org/10.1371/journal.pbio.0060182

53. Merkle FT, Mirzadeh Z, Alvarez-Buylla A (2007) Mosaic organization of neural stem cells in the adult brain. Science 317(5836):381-384. https://doi.org/10.1126/science.1144914

54. Ming GL, Song H (2011) Adult neurogenesis in the mammalian brain: significant answers and significant questions. Neuron 70(4):687-702. https://doi.org/10.1016/j.neuron.2011.05.001

55. Miraglia S, Godfrey W, Yin AH, Atkins K, Warnke R, Holden JT, Bray RA, Waller EK, Buck DW (1997) A novel five-transmembrane hematopoietic stem cell antigen: isolation, characterization, and molecular cloning. Blood 90(12):5013-5021. https://doi.org/10.1182/blood.V90.12.5013

56. Mizutani K, Yoon K, Dang L, Tokunaga A, Gaiano N (2007) Differential Notch signaling distinguishes neural stem cells from intermediate progenitors. Nature 449(7160):351-355. https://doi.org/10.1038/nature06090

57. Morrison SJ, Spradling AC (2008) Stem cells and niches: mechanisms that promote stem cell maintenance throughout life. Cell 132(4):598-611. https://doi.org/10.1016/j.cell.2008.01.038

58. Mothe AJ, Tator $\mathrm{CH}$ (2005) Proliferation, migration, and differentiation of endogenous ependymal region stem/progenitor cells following minimal spinal cord injury in the adult rat. Neuroscience 131(1):177-187. https://doi.org/10.1016/j.neuroscience.2004.10.011

59. Nagao M, Sugimori M, Nakafuku M (2007) Cross talk between notch and growth factor/cytokine signaling pathways in neural stem cells. Mol Cell Biol 27(11):3982-3994. https://doi.org/10.1128/MCB.00170-07

60. Nakafuku M, Nagao M, Grande A, Cancelliere A (2008) Revisiting neural stem cell identity. Proc Natl Acad Sci U S A 105(3):829-830. https://doi.org/10.1073/pnas.0711637105

61. Ohsawa R, Ohtsuka T, Kageyama R (2005) Mash1 and Math3 are required for development of branchiomotor neurons and maintenance of neural progenitors. J Neurosci 25(25):5857-5865. https://doi.org/10.1523/JNEUROSCI.4621-04.2005 
62. Peng J, Andersen JK (2011) Mutant alpha-synuclein and aging reduce neurogenesis in the acute 1methyl-4-phenyl-1,2,3,6-tetrahydropyridine model of Parkinson's disease. Aging Cell 10(2):255-262. https://doi.org/10.1111/j.1474-9726.2010.00656.x

63. Pfenninger CV, Roschupkina T, Hertwig F, Kottwitz D, Englund E, Bengzon J, Jacobsen SE, Nuber UA (2007) CD133 is not present on neurogenic astrocytes in the adult subventricular zone, but on embryonic neural stem cells, ependymal cells, and glioblastoma cells. Cancer Res 67(12):57275736. https://doi.org/10.1080/1061186X.2018.1479756

64. Pfenninger CV, Steinhoff C, Hertwig F, Nuber UA (2011) Prospectively isolated CD133/CD24-positive ependymal cells from the adult spinal cord and lateral ventricle wall differ in their long-term in vitro self-renewal and in vivo gene expression. Glia 59(1):68-81. https://doi.org/10.1002/glia.21077

65. Reya T, Morrison SJ, Clarke MF, Weissman IL (2001) Stem cells, cancer, and cancer stem cells. Nature 414(6859):105-111. http://dx.doi.org/10.1038/35102167

66. Scheer N, Groth A, Hans S, Campos-Ortega JA (2001) An instructive function for Notch in promoting gliogenesis in the zebrafish retina. Development 128(7):1099-1107

67. Shan X, Chi L, Bishop M, Luo C, Lien L, Zhang Z, Liu R (2006) Enhanced de novo neurogenesis and dopaminergic neurogenesis in the substantia nigra of 1-methyl-4-phenyl-1,2,3,6-tetrahydropyridineinduced Parkinson's disease-like mice. Stem Cells 24(5):1280-1287.

https://doi.org/10.1634/stemcells.2005-0487

68. Shimizu T, Kagawa T, Inoue T, Nonaka A, Takada S, Aburatani H, Taga T (2008) Stabilized betacatenin functions through TCF/LEF proteins and the Notch/RBP-Jkappa complex to promote proliferation and suppress differentiation of neural precursor cells. Mol Cell Biol 28(24):7427-7441. https://doi.org/10.1128/MCB.01962-07

69. Shi M, Hu ZL, Zheng MH, Song NN, Huang Y, Zhao G, Han H, Ding YQ (2012) Notch-Rbpj signaling is required for the development of noradrenergic neurons in the mouse locus coeruleus. J Cell Sci 125(Pt 18):4320-4332. https://doi.org/10.1242/jcs.102152

70. Singh SK, Hawkins C, Clarke ID, Squire JA, Bayani J, Hide T, Henkelman RM, Cusimano MD, Dirks PB (2004) Identification of human brain tumour initiating cells. Nature 432(7015):396-401. https://doi.org/10.1038/nature03128

71. Song X, Call GB, Kirilly D, Xie T (2007) Notch signaling controls germline stem cell niche formation in the Drosophila ovary. Development 134(6):1071-1080. https://doi.org/10.1242/dev.003392

72. Spassky N, Merkle FT, Flames N, Tramontin AD, Garcia-Verdugo JM, Alvarez-Buylla A (2005) Adult ependymal cells are postmitotic and are derived from radial glial cells during embryogenesis. $\mathrm{J}$ Neurosci 25(1):10-18. https://doi.org/10.1523/JNEUROSCI.1108-04.2005

73. Sun C, Ou X, Farley JM, Stockmeier C, Bigler S, Brinton RD, Wang JM (2012) Allopregnanolone increases the number of dopaminergic neurons in substantia nigra of a triple transgenic mouse model of Alzheimer's disease. Curr Alzheimer Res 9(4):473-480. https://doi.org/10.2174/156720512800492567 
74. Takizawa T, Ochiai W, Nakashima K, Taga T (2003) Enhanced gene activation by Notch and BMP signaling cross-talk. Nucleic Acids Res 31(19):5723-5731. https://doi.org/10.1093/nar/gkg778

75. Tanigaki K, Nogaki F, Takahashi J, Tashiro K, Kurooka H, Honjo T (2001) Notch1 and Notch3 instructively restrict bFGF-responsive multipotent neural progenitor cells to an astroglial fate. Neuron 29(1):45-55. https://doi.org/10.1016/S0896-6273(01)00179-9

76. Uchida N, Buck DW, He D, Reitsma MJ, Masek M, Phan TV, Tsukamoto AS, Gage FH, Weissman IL (2000) Direct isolation of human central nervous system stem cells. Proc Natl Acad Sci U S A 97(26):14720-14725. https://doi.org/10.1073/pnas.97.26.14720

77. Wang T, Ye X, Bian W, Chen Z, Du J, Li M, Zhou P, Cui H, Ding YQ, Qi S, Liao M, Sun C (2019) Allopregnanolone modulates GABAAR-dependent CaMKIIdelta3 and BDNF to protect SH-SY5Y cells against 6-OHDA-induced damage. Front Cell Neurosci 13:569. https://doi.org/10.3389/fncel.2019.00569

78. Weigmann A, Corbeil D, Hellwig A, Huttner WB (1997) Prominin, a novel microvilli-specific polytopic membrane protein of the apical surface of epithelial cells, is targeted to plasmalemmal protrusions of non-epithelial cells. Proc Natl Acad Sci U S A 94(23):12425-12430. https://doi.org/10.1073/pnas.94.23.12425

79. Weill-Engerer S, David JP, Sazdovitch V, Liere P, Eychenne B, Pianos A, Schumacher M, Delacourte A, Baulieu EE, Akwa Y (2002) Neurosteroid quantification in human brain regions: comparison between Alzheimer's and nondemented patients. J Clin Endocrinol Metab 87(11):5138-5143. https://doi.org/10.1210/jc.2002-020878

80. Xie MQ, Chen ZC, Zhang P, Huang HJ, Wang TT, Ding YQ, Qi SS, Zhang C, Chen SX, Zhou P, Shao CC, Liao M, Sun CY (2017) Newborn dopaminergic neurons are associated with the migration and differentiation of SVZ-derived neural progenitors in a 6-hydroxydopamin-injected mouse model. Neuroscience 352:64-78. https://doi.org/10.1016/j.neuroscience.2017.03.045

81. Yamamoto N, Tanigaki K, Han H, Hiai H, Honjo T (2003) Notch/RBP-J signaling regulates epidermis/hair fate determination of hair follicular stem cells. Curr Biol 13(4):333-338. https://doi.org/10.1016/S0960-9822(03)00081-2

82. Yoon K, Gaiano N (2005) Notch signaling in the mammalian central nervous system: insights from mouse mutants. Nat Neurosci 8(6):709-715. https://doi.org/10.1038/nn1475

83. Zhang P, Xie MQ, Ding YQ, Liao M, Qi SS, Chen SX, Gu QQ, Zhou P, Sun CY (2015) Allopregnanolone enhances the neurogenesis of midbrain dopaminergic neurons in APPswe/PSEN1 mice. Neuroscience 290:214-226. https://doi.org/10.1016/j.neuroscience.2015.01.019

84. Zhao M, Janson LA (2009) Bromodeoxyuridine infused into the cerebral ventricle of adult mice labels nigral neurons under physiological conditions-a method to detect newborn nerve cells in regions with a low rate of neurogenesis. J Neurosci Methods 184(2):327-331. https://doi.org/10.1016/j.jneumeth.2009.08.007

85. Zhao M, Momma S, Delfani K, Carlen M, Cassidy RM, Johansson CB, Brismar H, Shupliakov O, Frisen J, Janson AM (2003) Evidence for neurogenesis in the adult mammalian substantia nigra. Proc Natl 


\section{Figures}

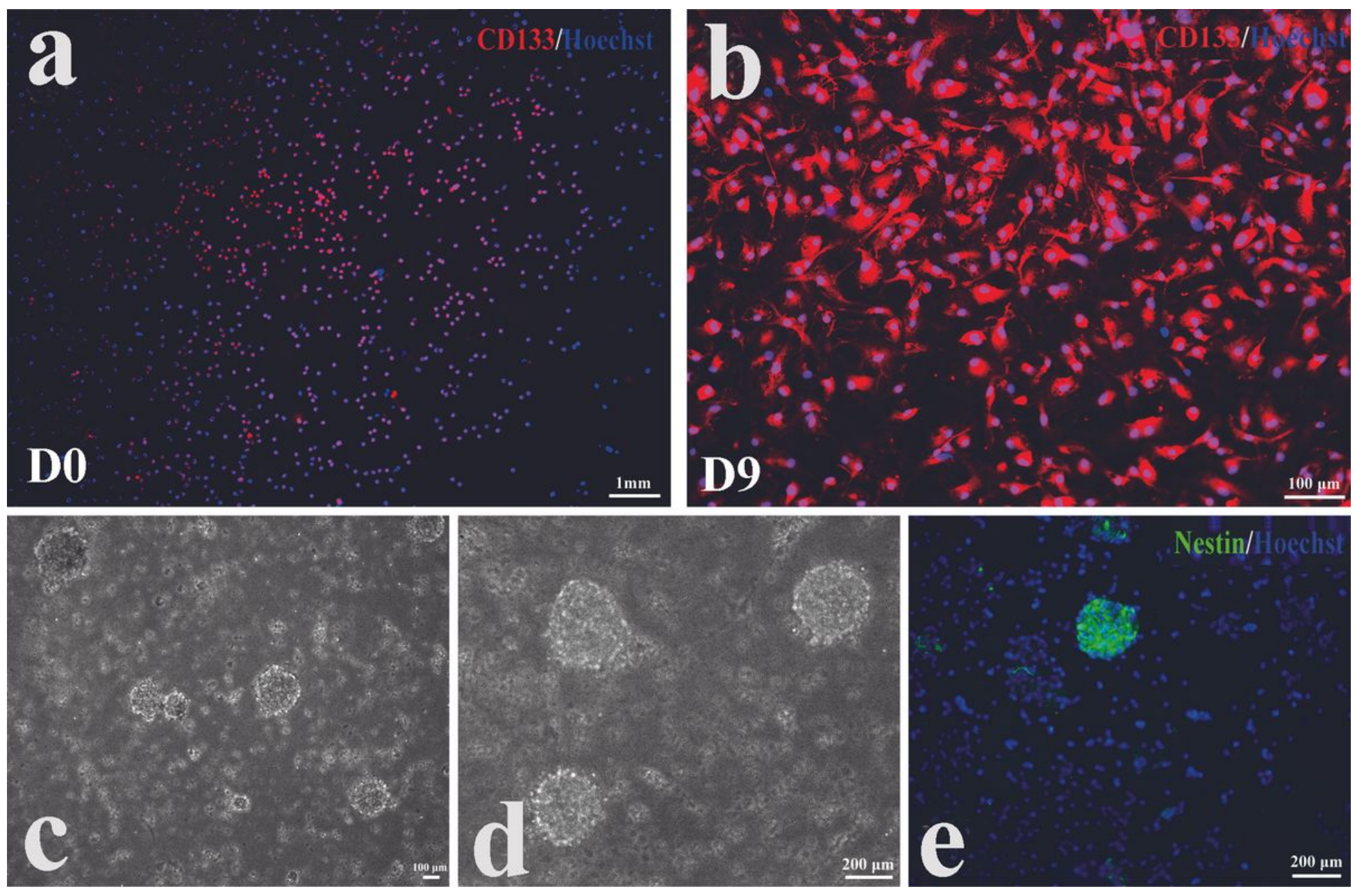

\section{Figure 1}

Identification of embryonic CD133-positive ependymal cells. a, b The red color of CD133-positive cells and blue color of Hoechst-positive nuclear were observed on DIV 0 (a) and 9 (b) from the forebrain of E12 mouse. c, $d$ The phase-contrast images of neuro-spheres were shown at a low (c) and high magnification (d) of visual field. e The fluorescent microscope displayed the neuro-spheres that were labelled by the green color of Nestin-positive NSCs and blue color of Hoechst-positive nuclear. Scale bar $=1 \mathrm{~mm}$ for image a or $100 \mu \mathrm{m}$ for images b-c or $200 \mu \mathrm{m}$ for images d-e. 


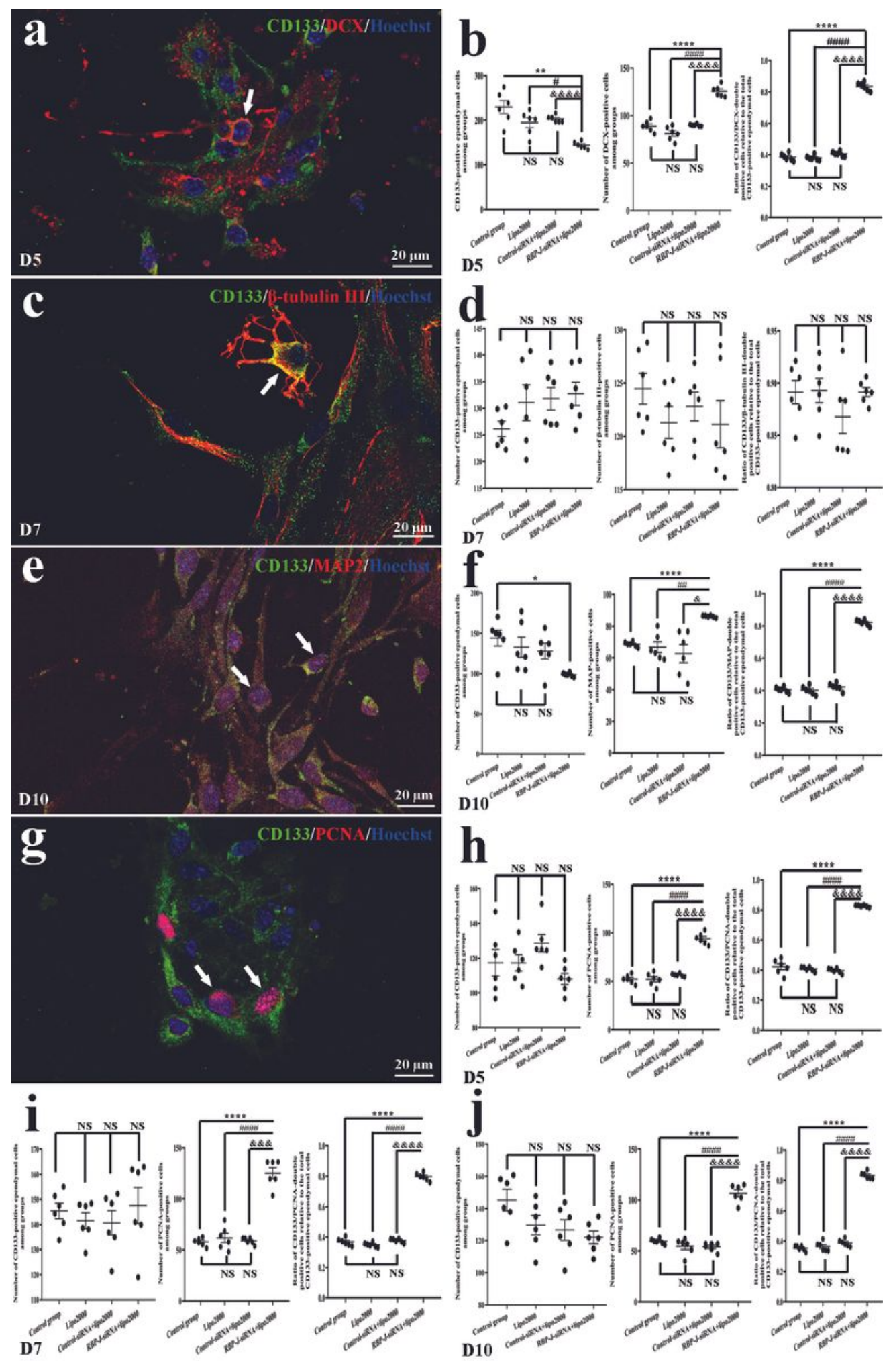

Figure 2

Distribution of CD133-, DCX-, $\beta$-tubulin III-, MAP2- and PCNA-positive cells and comparison of the number or ratio of these positive cells following RBP-J interference in vitro. a, c, e, g The representative images for CD133- (green color), DCX- (a) or $\beta$-tubulin III- (c) or MAP2- (e) or PCNA- (g) (red color) positive cells and Hoechst-positive nucleus (blue color) were visualized on DIV 5, 7 and 10 by the confocal laser scanning microscopy. The triple-labeled CD133/DCX/Hoechst-, CD133/ $\beta$-tubulin III/Hoechst-, 
CD133/MAP2/Hoechst- and CD133/PCNA/Hoechst-positive cells were denoted by the white arrows. Scale bar=20 $\mu \mathrm{m}$ for images a, $c$, e and g. b, d, f, h j The comparison of number of CD133-, DCX-, $\beta$-tubulin III-, MAP2- and PCNA-positive cells and ratio of double-positive cells among groups. The data were expressed as the mean $\triangle$ SEM of average in the 5 visual fields from 6 independent experiments of the primarily cultured CD133-positive ependymal cells and analyzed by ordinary one-way ANOVA with Tukey's test or

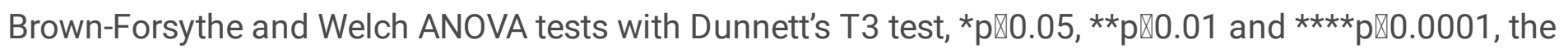
comparison of number of CD133-, DCX-, MAP- and PCNA-positive cells as well as ratio of CD133/DCX-, CD133/MAP2- and CD133/PCNA-double positive cells between the control group and RBP-J-

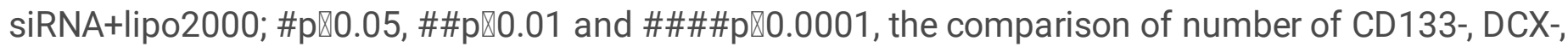
MAP- and PCNA-positive cells as well as ratio of CD133/DCX-, CD133/MAP2- and CD133/PCNA-double

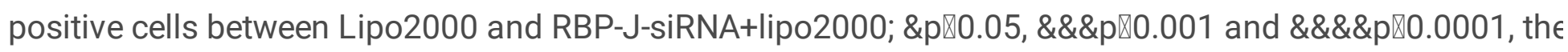
comparison of number of CD133-, DCX-, MAP2- and PCNA-positive cells as well as ratio of CD133/DCX-, CD133/MAP2- and CD133/PCNA-double positive cells between Control-siRNA+lipo2000 and RBP-JsiRNA+lipo2000. NS, no significance. 

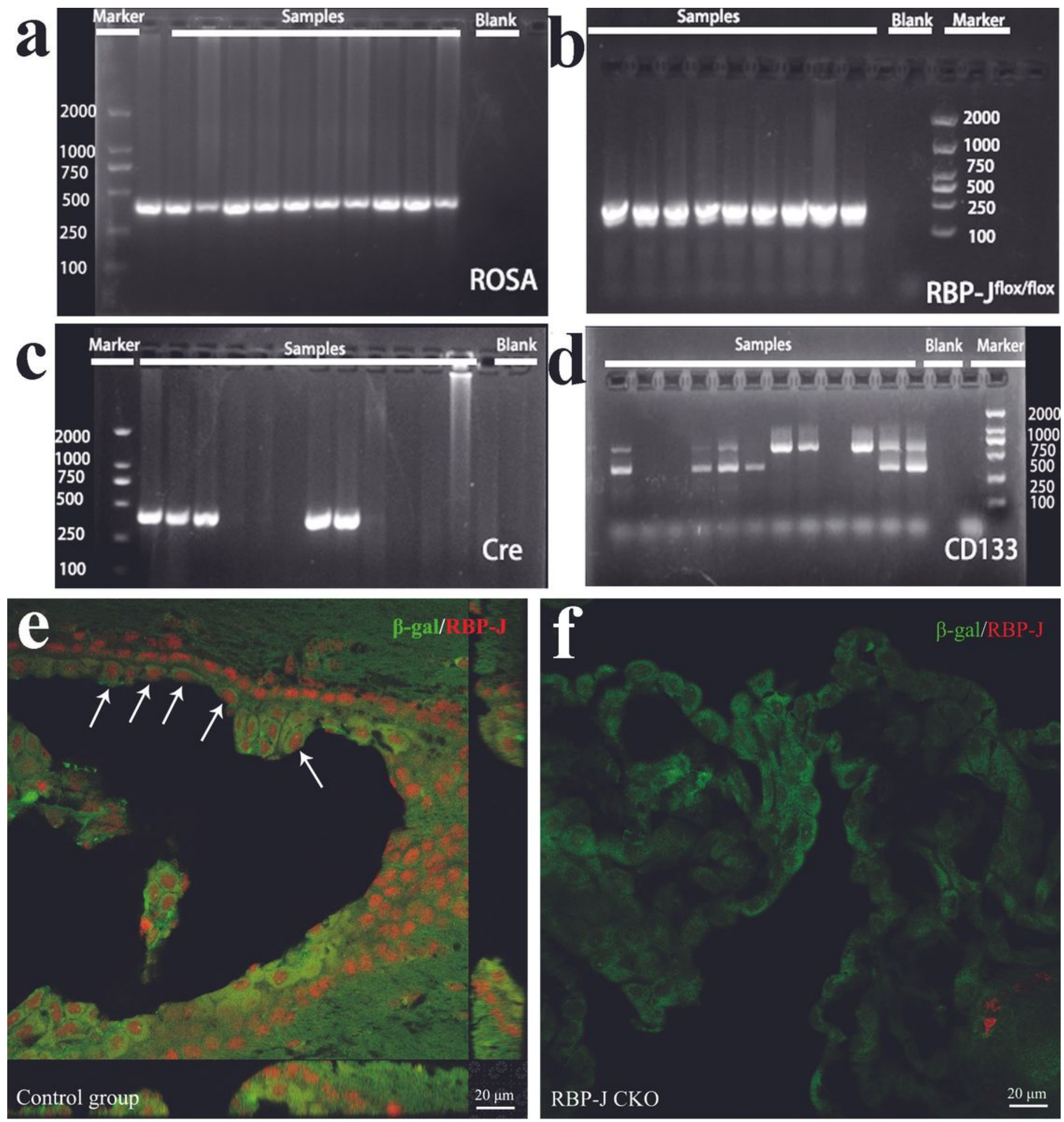

\section{Figure 3}

Identification of genotyping and expression of RBP-J in the transgenic mice. a d showed the genotyping for ROSA (a), RBP-Jflox/flox (b), Cre (c) and CD133 (d) using PCR primers in ROSA26-LacZ, RBPJflox/flox and CD133-CreERTM mice. PCR product was 300, 200, 300 and 586 (320) bp for ROSA, RBPJflox/flox, Cre and CD133, respectively. Molecular weight range of marker: 100 2000 bp. Blank: no DNA sample from the mouse toe in PCR reaction system. e-f showed RBP-J nuclear expression (red color) in 
the control group (e) and RBP-J CKO (f). $\beta$-Gal-stained CD133-positive ependymal cells were showed as the green color of fluorescence. $\beta$-Gal-positive cells co-expressed with RBP-J were denoted by white arrows. Scale bar $=20 \mu \mathrm{m}$ for images e and $\mathrm{f}$.
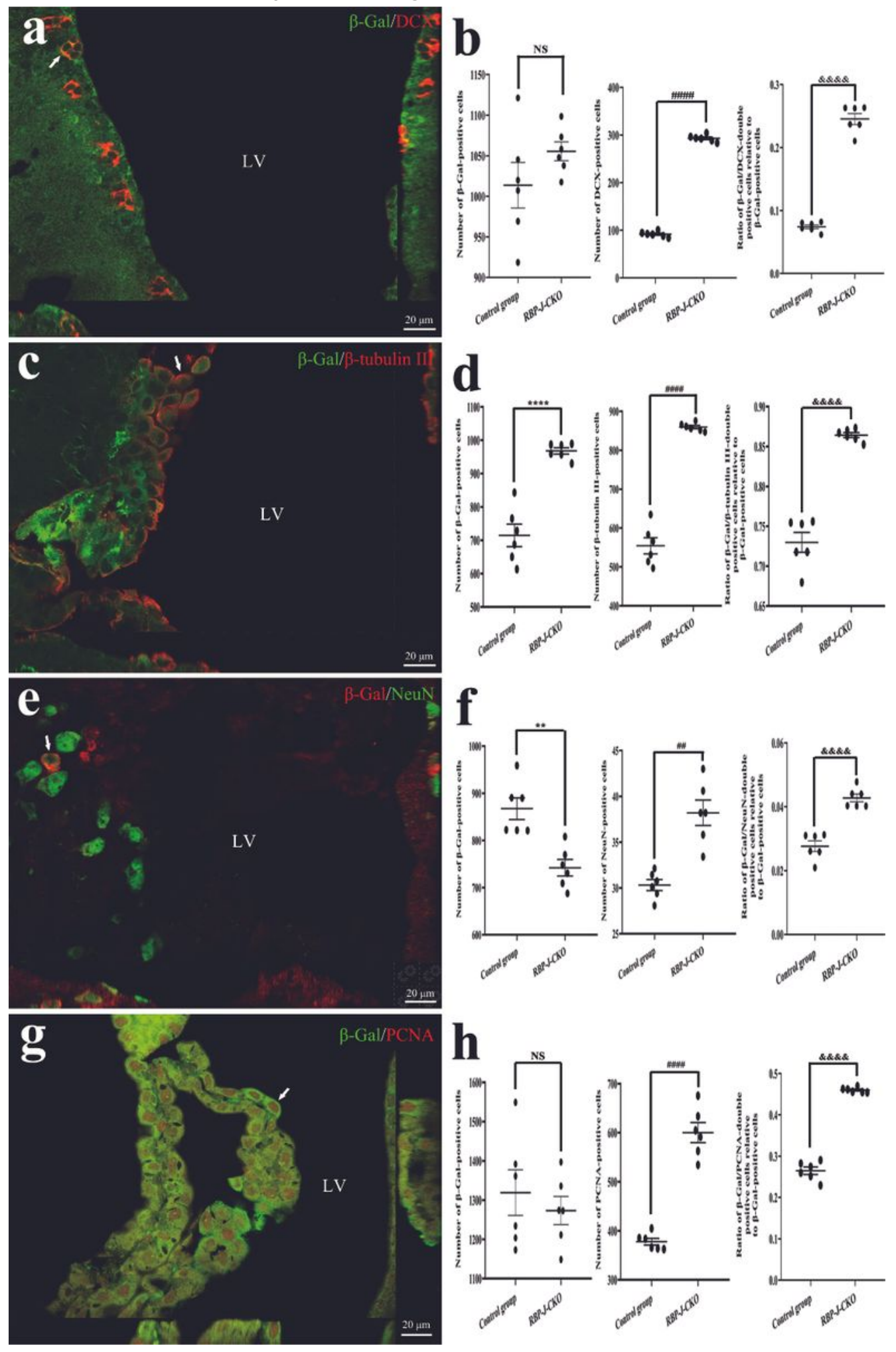

\section{Figure 4}

Distribution of $\beta$-Gal-, DCX-, $\beta$-tubulin III-, NeuN- and PCNA-positive cells in the LV-SVZ or ependymal layer and the comparison of number or ratio of these positive cells following RBP-J deletion in CD133-positive 
ependymal cells in vivo. a, c, e, $g$ The representative images for $\beta$-Gal- (green color for $a, c$ and $g$; red color for e), DCX- (a) or $\beta$-tubulin III- (c) or PCNA- (g) (red color), NeuN- (e, green color) positive cells were visualized in the LV-SVZ or ependymal layer in vivo by a confocal laser scanning microscopy. The $\beta$ Gal/DCX-, $\beta$-Gal/ $\beta$-tubulin III-, $\beta$-Gal/NeuN- and $\beta$-Gal/PCNA-double positive cells were denoted by the white arrows and their colocalization was verified in the three planes $(x, y$, and $z)$. Note: $L V$, lateral ventricle. Scale bar $=20 \mu \mathrm{m}$ for images $a, c, e$ and g. $b, d, f, h$ The comparison of number of $\beta-G a l-, D C X-, \beta-$ tubulin III-, NeuN- and PCNA-positive cells and ratio of double-positive cells between the control group and RBP-J CKO. The data were expressed as the mean \pm SEM of average from $\mathrm{N}=6$ in either RBP-J CKO mice or control groups and analyzed by unpaired two-tailed $t$ tests or unpaired $t$ test with Welch's correction, ${ }^{\star *} p$ $\llbracket 0.01$ and $* * \star * p \otimes 0.0001$, the comparison of number of $\beta$-Gal-positive cells between the control group and RBP-J CKO; \#\#p $₫ 0.01$ and \#\#\#\#p $₫ 0.001$, the comparison of number of DCX-, $\beta$-tubulin III-, NeuN- and PCNA-positive cells between the control group and RBP-J CKO; \&\&\&\&p $\mathbb{0 . 0 0 0 1}$, the comparison of ratio of $\beta$-Gal/DCX-, $\beta$-Gal/ $\beta$-tubulin III-, $\beta$-Gal/NeuN- and $\beta$-Gal/PCNA-double positive cells between the control group and RBP-J CKO. NS, no significance. 


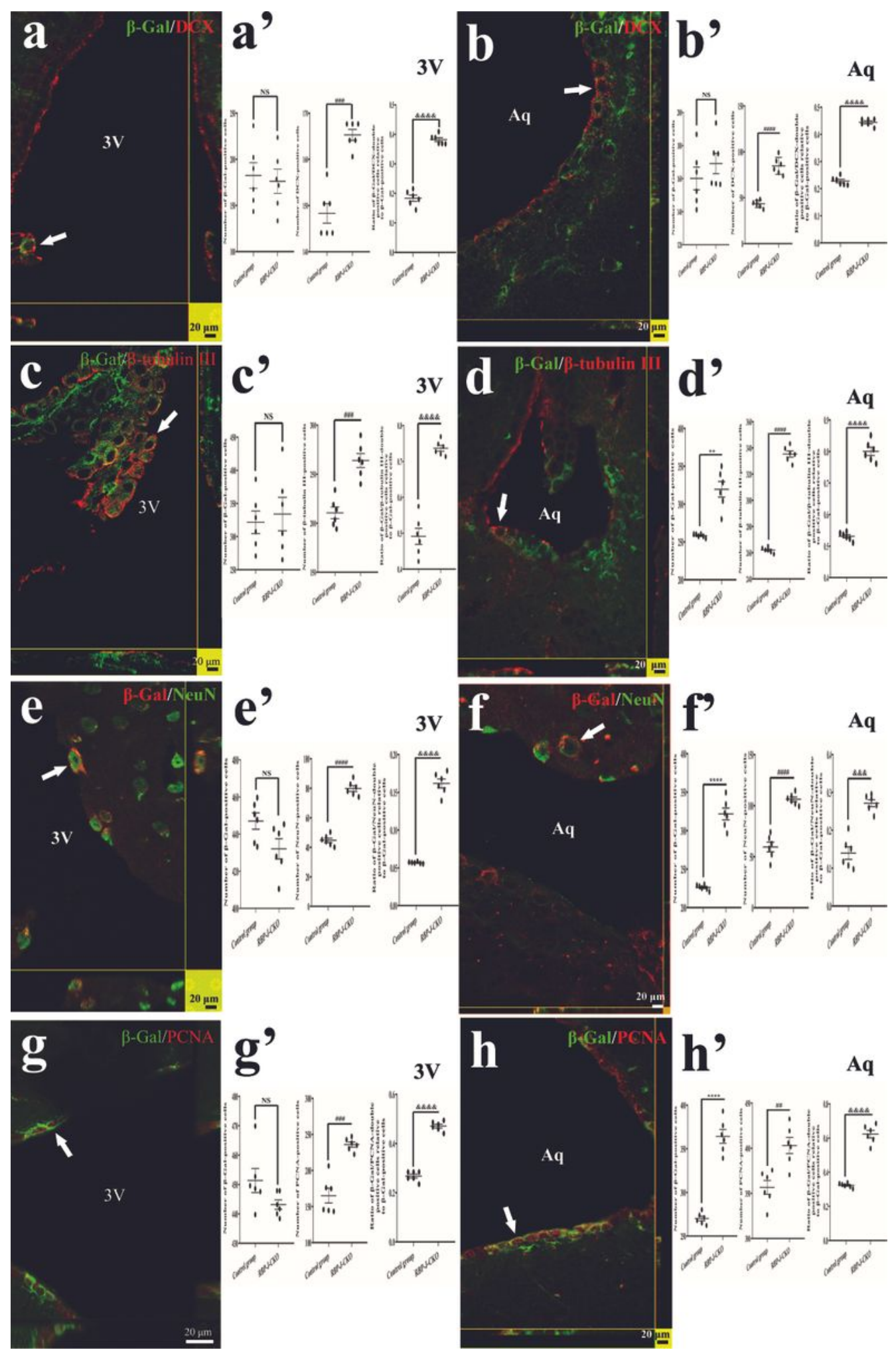

Figure 5

Distribution of $\beta$-Gal-, DCX-, $\beta$-tubulin III-, NeuN- and PCNA-positive cells in the 3V- or Aq-SVZ or ependymal layer and the comparison of number or ratio of these positive cells following RBP-J deletion in CD133positive ependymal cells in vivo. a h The representative images for $\beta$-Gal- (green color for a d, g-h; red color for e-f), DCX- $(a, b)$ or $\beta$-tubulin III- (c, d) or PCNA- $(g, h)$ (red color), NeuN- (e and f, green color) positive cells were visualized in the $3 \mathrm{~V}$ - $(a, c, e$ and $g)$ or Aq-SVZ or ependymal layer $(b, d, f a n d h)$ in vivo 
by a confocal laser scanning microscopy. The $\beta-G a l / D C X-, \beta-G a l / \beta$-tubulin III-, $\beta-G a l / N e u N-$ and $\beta$ Gal/PCNA-double positive cells were denoted by the white arrows and their colocalization was verified in the three planes $(x, y$, and $z)$. Note: $3 V$, the third ventricle; $A q$, cerebral aqueduct; Scale bar $=20 \mu \mathrm{m}$ for images a h. $a^{\prime} \sim h^{\prime}$ The comparison of number of $\beta$-Gal-, DCX-, $\beta$-tubulin III-, NeuN- and PCNA-positive cells and ratio of double-positive cells in the $3 V\left(a^{\prime}, c^{\prime}, e^{\prime}\right.$ and $\left.g^{\prime}\right)$ and $A q\left(b^{\prime}, d^{\prime}, f^{\prime}\right.$ and $\left.h^{\prime}\right)$ between the control group and RBP-J CKO. The data were expressed as the mean \pm SEM of average from $N=6$ in either RBP-J CKO mice or control groups and analyzed by unpaired two-tailed $t$ tests or unpaired $t$ test with Welch's correction, ${ }^{\star \star} \mathrm{p} \otimes 0.01$ and ${ }^{\star \star \star *} \mathrm{p} \otimes 0.0001$, the comparison of number of $\beta$-Gal-positive cells in the Aq between

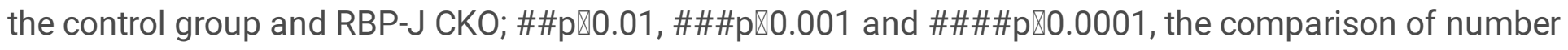
of DCX-, $\beta$-tubulin III-, NeuN- and PCNA-positive cells in the $3 \mathrm{~V}$ and Aq between the control group and RBP-

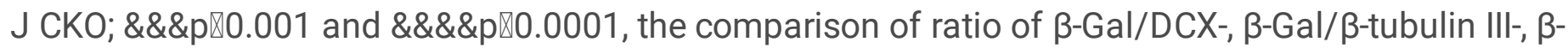
$\mathrm{Gal} / \mathrm{NeuN}$ - and $\beta$-Gal/PCNA-double positive cells in the $3 \mathrm{~V}$ and Aq between the control group and RBP-J CKO. NS, no significance. 

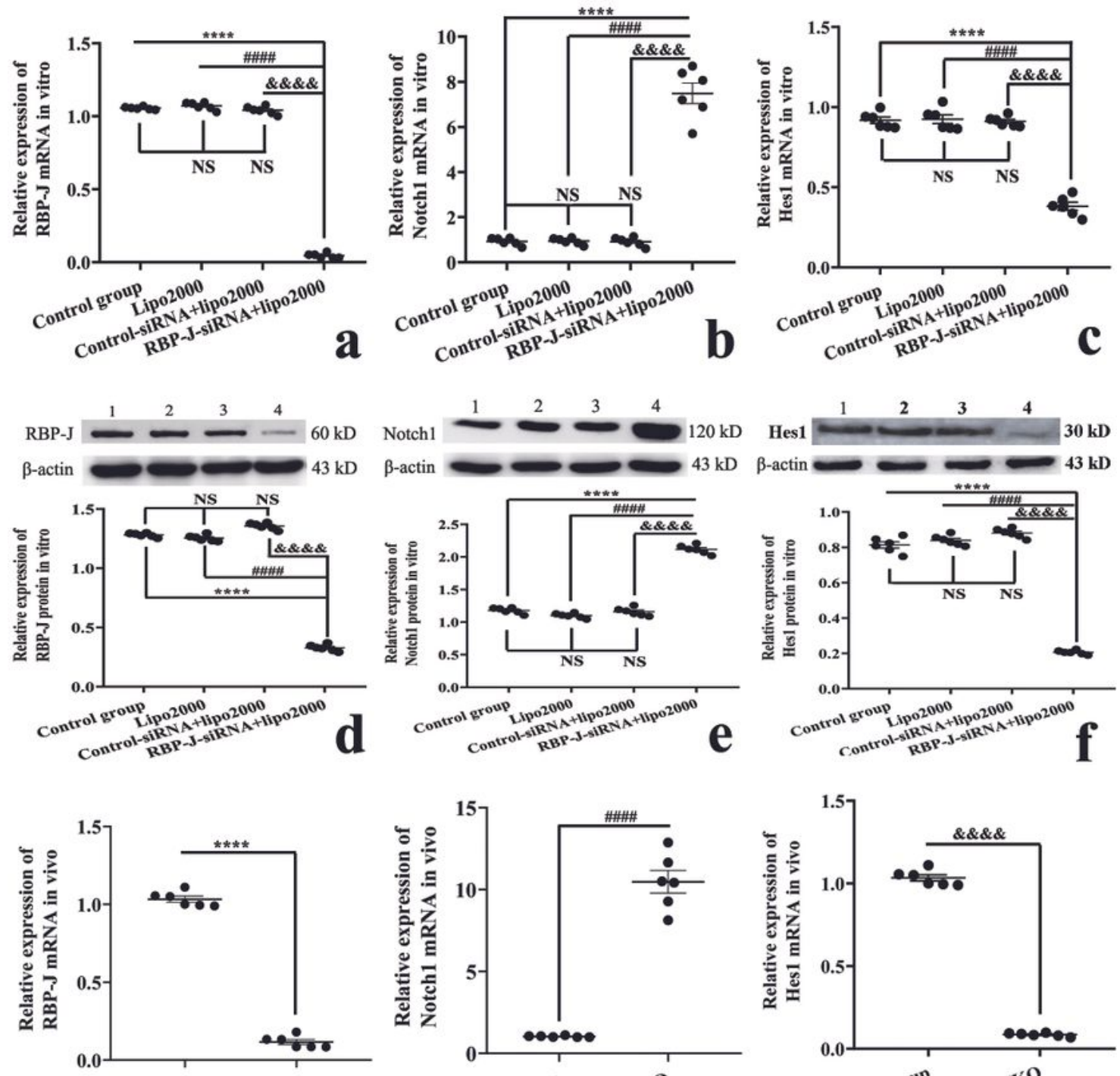

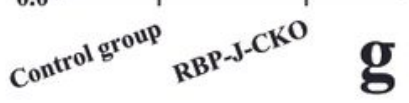
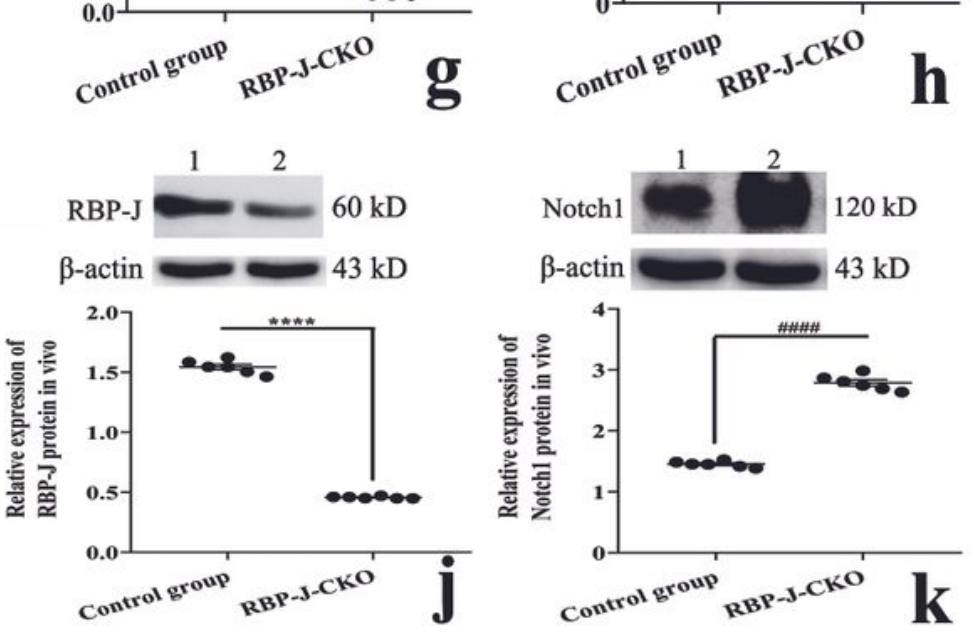
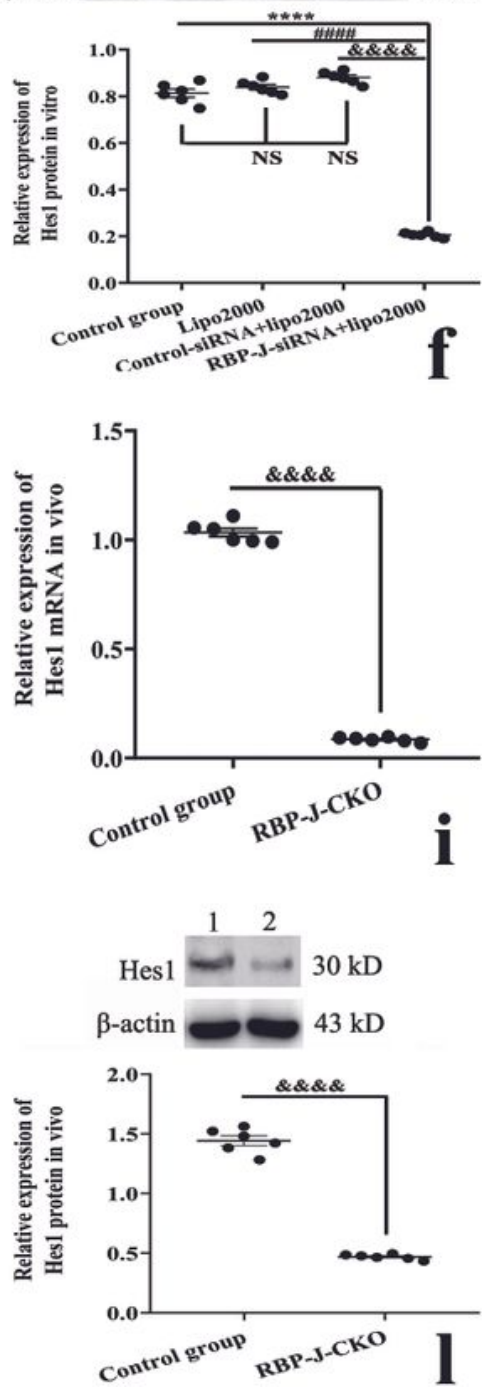

Figure 6

Relative expression levels for RBP-J-, Notch1- or Hes1-mRNA and their proteins in vitro or in vivo. a c The comparison of relative expression levels for RBP-J- (a), Notch1- (b) or Hes1-mRNA (c) among groups in vitro. The data were expressed as the mean \pm SEM of average from 6 independent experiments of the primarily cultured CD133-positive ependymal cells and analyzed by ordinary one-way ANOVA with Tukey's test or Brown-Forsythe and Welch ANOVA tests with Dunnett's T3 test, $* \star * \star p \otimes 0.0001$, the comparison of 
relative expression levels for RBP-J-, Notch1- and Hes1-mRNA between RBP-J-siRNA+lipo2000 and the control group; \#\#\#\#p\0.0001, the comparison of relative expression levels for RBP-J-, Notch1- and Hes1mRNA between RBP-J-siRNA+lipo2000 and Lipo2000; \&\&\&\&p囚0.0001, the comparison of relative expression levels for RBP-J-, Notch1- and Hes1-mRNA between RBP-J-siRNA+lipo2000 and ControlsiRNA+lipo2000. NS, no significance. $d \sim f$ The representative protein bands for RBP-J (60 kD, d), Notch1 $(120 \mathrm{kD}, \mathrm{e})$ or Hes $1(30 \mathrm{kD}, \mathrm{f})$ and the comparison of their relative protein expression levels among groups in vitro. Lane 1 4: the control group, Lipo2000, Control-siRNA+lipo2000 and RBP-J-siRNA+lipo2000. $\beta$ actin (43 kD): loading control. The data were expressed as the mean \pm SEM of average from 6 independent experiments of the primarily cultured CD133-positive ependymal cells and analyzed by ordinary one-way ANOVA with Tukey's test or Brown-Forsythe and Welch ANOVA tests with Dunnett's T3 test, $\star \star \star \star p \otimes 0.0001$, the comparison of relative protein expression level for RBP-J, Notch1 and Hes1

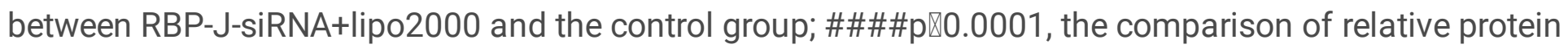
expression level for RBP-J, Notch1 and Hes1 between RBP-J-siRNA+lipo2000 and Lipo2000; \&\&\&\&p》 0.0001, the comparison of relative protein expression level for RBP-J, Notch1 and Hes1 between RBP-JsiRNA+lipo2000 and Control-siRNA+lipo2000. NS, no significance. g i The comparison of relative expression levels for RBP-J- (g), Notch1- (h) or Hes1-mRNA (i) in the LV-wall tissue between the control group and RBP-J CKO. The data were expressed as the mean \pm SEM of average from N=6 in either RBP-J CKO mice or control groups and analyzed by unpaired two-tailed $t$ tests or unpaired $t$ test with Welch's correction, ${ }^{\star \star \star \star} \mathrm{p} \otimes 0.0001$, the comparison of relative expression level for RBP-J-mRNA between the control group and RBP-J CKO; \#\#\#\#p \0.0001, the comparison of relative expression level for Notch1-mRNA between the control group and RBP-J CKO; \&\&\&\&p\0.0001, comparison of relative expression level for Hes1-mRNA between the control group and RBP-J CKO. j I The representative protein bands for RBP-J (60 kD, j), Notch1 (120 kD, k) or Hes1 (30 kD, I) and the comparison of their relative protein expression levels in the LV-wall tissue between the control group and RBP-J CKO. Lane 1 2: the control group and RBP-J CKO. $\beta$-actin (43 kD): loading control. The data were expressed as the mean \pm SEM of average from $N=6$ in either RBP-J CKO mice or the control group and analyzed by unpaired two-tailed t tests or unpaired t test with Welch's correction, $\star \star \star \star p \otimes 0.0001$, the comparison of relative protein expression level for RBP-J between the control group and RBP-J CKO; \#\#\#\#p \0.0001, the comparison of relative protein expression level for Notch1 between the control group and RBP-J CKO; \&\&\&\&p\0.0001, the comparison of relative protein expression level for Hes1 between the control group and RBP-J CKO.

\section{Supplementary Files}

This is a list of supplementary files associated with this preprint. Click to download.

- Fig4bDCXcells.pzf

- Fig4bbGalDCXdoublecells.pzf

- Fig4bbGalcells.pzf

- Fig.2bCD133DCXdoublecells.pzf

- Fig.2bCD133.pzf 
- Fig.2bDCX.pzf

- Fig.2dCD133.pzf

- Fig.2dTubulinCD133doublecells.pzf

- Fig.2dTubulin.pzf

- Fig.2fCD133MAPdoublecells.pzf

- Fig.2fCD133.pzf

- Fig.2fMAP.pzf

- Fig.2hCD1335d.pzf

- Fig.2hCD133PCNAdoublecells5d.pzf

- Fig.2hPCNA5d.pzf

- Fig.2iCD1337d.pzf

- Fig.2iCD133PCNAdoublecells7d.pzf

- Fig.2iPCNA7d.pzf

- Fig.2jCD13310d.pzf

- Fig.2jCD133PCNAdoublecells10d.pzf

- Fig.2jPCNA10d.pzf

- Fig.4dbGalcells.pzf

- Fig.4dbGalbtublindoublecells.pzf

- Fig.4dbtublin.pzf

- Fig.4fNeuN.pzf

- Fig.4fbGalNeuN.pzf

- Fig.4fbGal.pzf

- Fig.4hPCNA.pzf

- Fig.4hbGalPCNAdoublecells.pzf

- Fig.4hbGalcells.pzf

- Fig.5CbGal3V.pzf

- Fig.5CbGalbtublindoublecells3V.pzf

- Fig.5Cbtublincells3V.pzf

- Fig.5aDCXcells3V.pzf

- Fig.5abGalDCXdoublecells3V.pzf

- Fig.5abGalcells3V.pzf

- Fig.5bDCXAq.pzf

- Fig.5bbGalAq.pzf

- Fig.5bbGalDCXdoublecellsAq.pzf 
- Fig.5dbGalAq.pzf

- Fig.5dbGalbtublinAq.pzf

- Fig.5dbtublinAq.pzf

- Fig.5eNeuNcells3V.pzf

- Fig.5ebGalNeuNdoublecells3V.pzf

- Fig.5ebGalcells3V.pzf

- Fig.5fNeuNcellsAq.pzf

- Fig.5fbGalNeuNdoublecellsAq.pzf

- Fig.5fbGalcellsAq.pzf

- Fig.5gPCNAcells3V.pzf

- Fig.5gbGalcells3V.pzf

- Fig.5gbGalPCNAdoublecells3V.pzf

- Fig.5hPCNAAq.pzf

- Fig.5hbGalAq.pzf

- Fig.5hbGalPCNAdoublecellsAq.pzf

- Fig.6aRBPJmRNAcell.pzf

- Fig.6bNotch1mRNAcell.pzf

- Fig.6cHes11mRNAcell.pzf

- Fig.6dRBPJ1proteincell.pzf

- Fig.6eNotch1proteincell.pzf

- Fig.6fHes1proteincell.pzf

- Fig.6gRBPJmRNAmouse.pzf

- Fig.6hNotch1mRNAmouse.pzf

- Fig.6iHes1mRNAmouse.pzf

- Fig.6jRBPJproteinmouse.pzf

- Fig.6kNotch1proteinmouse.pzf

- Fig.6lHes1 proteinmouse.pzf

- WesterblotforRBPJinvitro.tif

- WesternblotforHes1 invitro.tif

- WesternblotforHes1 invivo.tif

- WesternblotforNotch1 invivo.tif

- WesternblotforNotch1 invitro.tif

- WesternblotforRBPJinvivo.tif 